\title{
Study on the Damage Model of Coal Rock Caused by Hydraulic Pressure and Electrical Impulse in Borehole
}

\author{
Xiankai Bao $\mathbb{D},{ }^{1}$ Jiaxing Cao $\mathbb{D}^{2},{ }^{2}$ Wenxiang Zheng, ${ }^{3}$ Junyu Guo, ${ }^{1}$ Yuan Liu, ${ }^{1}$ \\ and Jinchang Zhao ${ }^{4}$ \\ ${ }^{1}$ School of Civil Engineering, Inner Mongolia University of Science and Technology, Baotou Inner Mongolia 014010, China \\ ${ }^{2}$ State Key Laboratory of Coal Resources and Safe Mining, China University of Mining and Technology, Xuzhou 221116, China \\ ${ }^{3}$ School of Mining and Coal, Inner Mongolia University of Science and Technology, Baotou Inner Mongolia 014010, China \\ ${ }^{4}$ School of Mining Technology, Taiyuan University of Technology, Taiyuan 030024, China
}

Correspondence should be addressed to Jiaxing Cao; 18947257406@163.com

Received 21 October 2020; Revised 30 December 2020; Accepted 18 March 2021; Published 24 May 2021

Academic Editor: Andrea Brogi

Copyright (c) 2021 Xiankai Bao et al. This is an open access article distributed under the Creative Commons Attribution License, which permits unrestricted use, distribution, and reproduction in any medium, provided the original work is properly cited.

\begin{abstract}
The purpose of this study is to study the damage and fracturing effects of high-voltage discharge on coal-rock mass under the action of hydrostatic pressure. Based on the traditional damage evolution model and the change of the effective bearing area and stress around the microcrack of coal-rock mass on a microscopic scale, the expression of macroscopic damage variation of coal-rock mass under the action of electrohydraulic coupling was derived, and its damage constitutive relation was established. The high-voltage pulse water shock stress test of coal-rock mass under the conditions of different water pressures and voltages was carried out, and its damage numerical model was established by the ABAQUS/XFEM. The damage variable values of coal-rock mass with different electrohydraulic parameters were compared to characterize the generation and expansion of internal macroscopic cracks. From the results, it is shown that the damage variable based on the effective bearing area and stress around the crack can represent the morphology and expansion change of crack of coal-rock mass with different electrohydraulic parameters clearly and quantitatively. Different hydrostatic pressures and discharge voltages have influence on the damage variables of coal-rock mass, but different influencing degrees cause different damages on coal-rock mass. The damage of coal rock can be characterized by the change of the effective bearing area and stress around microcracks in coal body. So, stress testing and numerical simulation have verified the correctness of the damage model.
\end{abstract}

\section{Introduction}

The coalbed methane $(\mathrm{CBM})$ is an associated mineral resource with methane as the main component stored in the coalbed. Its occurrence state is mainly adsorbed on the surface of coal matrix particles and partially freed from coal pores. It is unconventional natural gas. It is clean, highquality energy, and chemical raw material that has risen internationally in the past $1 \sim 2$ decades. China is the third CBM reserve country in the world and has rich and evenly distributed coalbed gas $[1,2]$. Nevertheless, the CBM of China is generally characterized by low saturation, permeability, reservoir pressure and resource richness, and high metamorphism [3]. The current extraction rate is generally $30 \% \sim 40 \%$, and the mining efficiency is low. Some countries with a higher CBM extraction rate generally have an extraction rate of $30 \% \sim 60 \%$ (the maximum extraction rate is $80 \%)$ [4]. At present, there are two main methods for improving the extraction rate of low-permeability coalbed methane. One of them is to change the occurrence state of CBM. The gas adsorbed on the inner surface of e pores of the coal matrix is changed from the adsorption state to the free state, thus improving the diffusion ability of CBM from the matrix and the micropores to the crack; You et al. [5] studied the effect of three surfactants in the fracturing fluid on the adsorption-desorption processes of coalbed methane (CBM). It was studied by conducting an isothermal adsorption-desorption experiment. The adsorption capacity of surfactants and the wettability of the coal surface were also systematically investigated to illustrate the impact of 
surfactants. The effect of fracturing fluid was proved to be of great significance for coalbed methane desorption and improved coalbed methane extraction rate. Zhu et al. [6] studied CBM in composite desorption mode and found that the desorption rate of CBM was negatively correlated with the water content, and the desorption amount showed an increasing trend with the decrease of the water content. The other is to expand the migration channel of gas; through the external load, the expansion of internal cracks of the coal seam is improved, and more complex network cracks are formed. It provides a channel for gas to flow inside the coal seam and allows the CBM to pass more cracks to the borehole (wellbore), which increases the gas permeability and improves the extraction efficiency. Li et al. [7] proposed to develop a method to increase the permeability of coal seam. It is realized by dissolving part of the coal matrix solvent and combining it with a physical destruction method to solve the problem of low permeability coal seam fracture connectivity. Lu et al. [8] proposed the high voltage electric pulse fracturing coal technology. He proved that this technology effectively and improved the coal seam fracture connectivity and increased its transport efficiency. It improved the coalbed methane production. Yan et al. [9] had proposed the synergistic technology of slitting and fracturing to increase the permeability, which has significantly improved the efficiency of gas extraction, in response to the problem of inadequate pressure release in the drill holes for extraction through the low permeability coal seam. Compared with the first method, the second method is more widely used and has a stronger guiding significance for engineering practice.

Among the various methods to expand the CBM migration channel and improve the extraction efficiency of CBM wells, the reservoir-cracking and permeability improvement technique has the most significant influence in increasing the production of CBM. Therefore, it has been highly valued and favored by CBM well extraction technicians in various countries $[10,11]$. More than 90\% CBM wells in the United States use various cracking techniques to increase the production of CBM. The application and development of various cracking and antireflection technique in China are also very rapid. Most high-yield CBM wells have adopted this stimulation technique. This means that the artificial methods for the structural transformation of the coal-rock reservoir layer, the increase of crack extension range, the weakening of coal-rock strength, and the improvement of permeability are effective ways to improve the extraction efficiency. Among them, hydraulic fracturing is not only used for testing seismic sources $[12,13]$ but also has been widely used in the development and exploitation of low-permeability oil and gas fields as a major measure to increase production in oil and gas wells. Zhong et al. [14] proposed that the stimulation of hydraulic fracturing on a combination of depressurization with thermal stimulation for natural gas hydrate (NGH) exploitation from challenging ocean hydrate reservoirs is investigated in this study. The influence of fracture permeability, well spacing on hydrate exploitation, and the enhancement effect of hydraulic fracturing on different well spacings is numerically investigated. The results show that hydraulic fracturing has a significant improvement in hydrate exploitation performance, including hydrate decomposition behavior, gas production behavior, gas recovery ratio, and energy ratio. Zhou et al. [15] conducted a simulation and experimental study on hydraulic fracturing of the low-permeability coal seam to solve the difficult problems of extraction, heavy workload, and low efficiency of gas extraction in a low-permeability coal seam. The results showed that the fracture damage range of coal seam before and after hydraulic fracturing was up to $14 \mathrm{~m}$, and the permeability of the coal seam increased 67 times. $\mathrm{Wu}$ [16] studied the propagation law of hydraulic fracturing in the coal rock complexes, and the maximum opening of hydraulic fracturing in the parallel stratigraphic direction of the coal was $1.292 \mathrm{~mm}$, the maximum opening in the vertical stratigraphic direction of the coal was $0.952 \mathrm{~mm}$, and the maximum opening in the vertical stratigraphic direction of the sandy mudstone was $0.816 \mathrm{~mm}$ after the implementation of hydraulic fracturing.

Hydraulic fracturing has proven to be very effective in gas extraction and treatment, and it has also exposed some problems. Wang [17] conducted hydraulic fracturing test for coal seam wells with low permeability. It realized the purpose of pressure relief and permeability enhancement in lowpermeability coal seam, which greatly increased the extraction amount of gas from the low-permeability coal seam. Wang et al. [18] implemented the technique of directional hydraulic fracturing, where slits and hydraulic fracturing widen the range of gas pressure drop and reduce the time required to complete extraction. While hydraulic fracturing was carried out, some problems were also exposed. Gagnon et al. [19] suggested that environmental pollution problems such as methane pollution and other chemical pollution are the key problems to be solved based on hydraulic fracturing technology for shale gas wells. Bao [20] conducted a comparative experiment $t$ based on high-pressure electric pulse hydraulic fracturing and traditional hydraulic fracturing. He found that traditional hydraulic fracturing technology exists limitations. They are insufficient fracturing capacity and long fracturing time in the application process. In order to further improve the traditional hydraulic fracturing effect, some new hydraulic fracturing techniques have emerged in recent years. Based on the electrohydraulic effect, $\mathrm{Li}$ et al. $[21,22]$ proposed a high-voltage electric pulse hydraulic fracturing and permeability improvement technique of coal seam. The principle of this technique is to use the water shock vibration effect formed by the high-voltage electric pulse discharge in the crack tip of coal seam to break, develop, and penetrate the microcracks, thus achieving the purpose of reducing the resistance and improving the permeability and extraction efficiency of CBM. The specific principle was shown in Figure 1. The electrohydraulic effect produced by a high-voltage discharge pulse can also be referred to as the electrical explosion in the liquid (or electrohydraulic explosion). Li [23] and Yan et al. [24, 25] studied the static breakdown, detonation, and heating effects of pulse discharge in hydrostatic pressure, the breakdown and detonation dynamic load, and the cracking characteristics of coal-rock mass through experiments and numerical calculations. In order to study the method in depth, Bian et al. [26, 

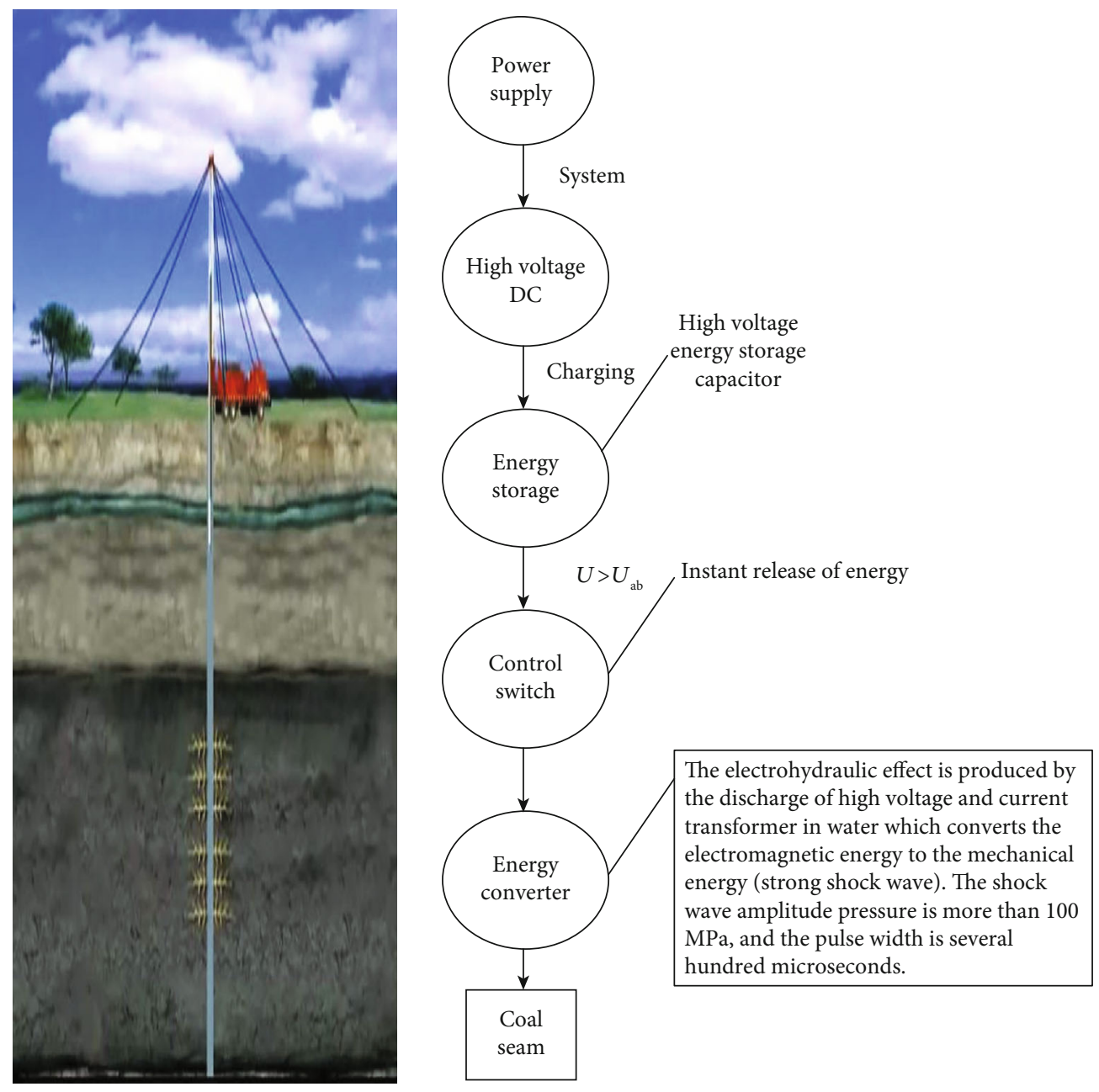

FIGURE 1: Composite fracturing-strengthening coal seam technique principle of high-pressure discharge pulse water shock.

27] analyzed the pulse wave and expansion mechanism of pulse discharge with different hydrostatic pressures and discharge voltages under the action of coupling hydrostatic pressure and studied the fracturing effect of concrete specimen with different hydrostatic pressures and discharge parameters. Bao et al. $[28,29]$ studied the coupling mechanism and the electro-solid-liquid law and used the high-voltage detection and CT scanning technique to preliminarily evaluate the damage characteristics and fracturing cracks effects of for high-voltage electric pulse hydraulic fracturing coal with different test parameters.

In recent years, in order to explore the micromechanical mechanism of macroscopic fracture of hydraulic fracturing coal-rock mass, domestic and foreign scholars have carried out much types of research on the microscopic damage laws of coal-rock mass and macroscopic fracture characteristics. Zhao et al. [30] studied the proposed equivalent Burgers model lays the foundations for revealing the rheological behavior of fractured rock mass subjected to the combined action of hydraulic pressure and stresses. Peng et al. [31] studied the macroscopic fracture characteristics of granite under different loading conditions based on different temperatures and depths. Wang et al. [32] studied the fracture characteristics of granite under impact loading and found that the fracture zone area and crater depth are variables depending on the impact angle at constant impact velocity. Based on the characteristics of probability and statistical models, Hu et al. [33] consider adsorbed-gas-induced swelling stress and erosion, pore/fracture-induced damage and failure to coal skeleton, the new effective stress equation, damage deformation control equation, and constitutive model for gas-bearing coal which are established. Based on the principle of statistics and fractal theory, we combined the microstructure characteristics of coal and established the control equation of the fracture field distribution. Based on the derivation of coal matrix strain, Liu et al. [34] established a coal matrix stress model under various stress conditions and a mechanical model for pulverized coal crushing. Tang et al. [35] studied the microdamage characteristics of sandstone in the loading process of different confining pressures and axial stress by using a triaxial compression test equipment. With the increase of axial stress, the degree of plastic deformation and the microdamage factor of sandstone increase continuously. The strength of sandstone gradually deteriorates, and the microdamage factor of the specimen basically obeys the Gauss function distribution. 
The microdamage of specimen increases with the axial stress from the edge of the observation surface to the center. Voyiadjis [36] analyzed the damage variable in the coalrock damage process. Based on the evolution of the fatigue damage variable of coal-rock mass under the action of cyclic loading, Xiao [37] proposed a time-dependent damage variable and derived the damage constitutive model under the action of cyclic loading. Liu et al. [38] found that the gas permeability of coal seam was the main factor that determines the efficiency of gas extraction in mines. It was closely related to coal damage. The permeability of gasbearing coal increases exponentially with the development of damage. Li et al. [39] comprehensively discussed the effective stress of coal-rock mass under the action of external load and established a statistical constitutive model of elastoplastic damage. Based on the variable amplitude loading, Liu [40] derived the variation law of fatigue damage variable and deduced and established the constitutive model.

At present, the dynamic mechanical characteristics, dynamic damage mechanism, damage mode and crack initiation, and evolution mechanism of coal-rock mass under the action of high-voltage discharge pulse water shock have still been in an exploration stage. In order to study the fracturing effect of coal-rock mass with different electrohydraulic coupling parameters, the damage of microcracks in the damage process of coal-rock mass and the occurrence and expansion of macrocracks were quantitatively evaluated. Zhao et al. [41-43] investigated fracture toughness and subcritical crack growth of different rock and studied weakening the effects of different parameters. Based on Lemaitre damage strain equivalent principle [44-46], the damage variable of coalrock mass was defined, and the damage constitutive equation was established by combining the damaged area with effective stress of fine microfracture, which achieved the purpose of quantitatively evaluating the specific damage of coal-rock mass under the action of electrohydraulic coupling. The high-pressure electric pulse hydraulic fracturing test under the action of electrohydraulic coupling was designed and implemented. Based on the hydrostatic pressure and the electric pulse load electrohydraulic coupling, the numerical simulation was carried out by the ABAQUS/XFEM $[47,48]$. Based on the unit damage area and effective stress, the feasibility and correctness of damage variables and constitutive models were verified by the damage and deformation characteristics of coal-rock mass under the action of different loads.

\section{Establishment of Electrohydraulic Coupling Damage Model for Coal-Rock Mass}

2.1. Mechanism of Electrohydraulic Coupling Damage. Under the action of hydrostatic pressure and electric pulse load, the damage caused by coal-rock mass is mainly divided into two stages. The first stage is the damage of coal-rock mass under the action of hydrostatic pressure. There are a lot of microdefects inside the coal rock. When the hydrostatic pressure is applied to the coal-rock mass, the original microcracks existing in the coal-rock mass itself are initiated, expanded, and merged. This is the first stage of damage, that is, the solidliquid coupling damage stage. Under the action of hydro- static pressure, the electric pulse load is applied. As the pulse load repeatedly impacts, the crack expands and penetrates continuously, and the damage degree of coal rock increases continuously. This is the second stage, namely, the electrohydraulic coupling damage stage. The damage state effect can be represented by the damage variable as follows:

$$
D_{2}=D_{1}+D_{1}{ }^{\prime}-D_{1} D_{1}^{\prime},
$$

where $D_{2}$ is the total damage variable of coal-rock mass under the action of hydrostatic pressure and electric pulse loading electrohydraulic coupling, $D_{1}$ is the damage variable under the action of hydrostatic pressure of coal-rock mass, $D_{1}{ }^{\prime}$ is the damage variables in coal-rock mass under electrical impulse loading, and $D_{1} D_{1}{ }^{\prime}$ is the damage coupling term.

2.2. Damage Evolution Constitutive Relation. In the process of high voltage electric pulse hydraulic fracturing of coalrock mass, the damage crack caused by the hydrostatic pressure and electric pulse pressure can be divided into macrocrack and micr-crack. The change of the macrofracture area is resulted from the generation and penetration of microcrack. Therefore, in the process of electric pulse hydraulic fracturing of coal-rock mass, the damage of the effective bearing area of coal-rock mass can be used to characterize the damage during the entire damage process. Based on the effective bearing area of coal-rock mass, the damage variable can be expressed as

$$
D_{2}=\frac{A_{1}-A_{2}}{A_{1}},
$$

where $A_{1}$ is the original effective bearing area of coal-rock mass, $\mathrm{m}^{2}$, and $A_{2}$ is the effective bearing area of coal-rock under the action of electrohydraulic coupling, $\mathrm{m}^{2}$.

As early as 1906, Professor Lemaitre proposed the strain equivalence criterion:

$$
\varepsilon=\frac{\sigma_{1}}{E_{2}}=\frac{\sigma_{2}}{E_{1}},
$$

where $\sigma_{1}$ is the original effective stress of coal-rock mass, $\mathrm{MPa}, \sigma_{2}$ is the effective stress of coal-rock mass under the coupling of liquid and electricity, $\mathrm{MPa}, E_{2}$ is the elastic modulus of coal-rock mass under the action of electrohydraulic coupling, $\mathrm{MPa}$, and $\varepsilon$ is the damage strain of coal-rock mass.

According to the Lemaitre equivalent strain hypothesis, Zhang [49] proposed the strain equivalence principle: when the coal-rock material is subjected to the force $F$, two damage states of material are taken. The effective stress in the base damaged state acting on the strain caused by the second damage state is equivalent to the effective stress of material in the second damage state acting on the strain caused by the first damage state. Therefore, the following formula was obtained.

$$
\sigma_{1} A_{1}=\sigma_{2} A_{2}=F \text {. }
$$

It can be seen from Formula (4) that if the coal-rock mass is defined as the base damage under the stress state, 
TABLE 1: Physical and mechanical parameters of coal-rock mass.

\begin{tabular}{cccccccc}
\hline $\begin{array}{l}\text { Parameters } \\
\text { of rock coal }\end{array}$ & $\begin{array}{c}\text { Bulk density } \\
\left(\mathrm{kN} / \mathrm{m}^{3}\right)\end{array}$ & $\begin{array}{c}\text { Tensile } \\
\text { strength } \\
(\mathrm{MPa})\end{array}$ & $\begin{array}{c}\text { Compressive } \\
\text { strength }(\mathrm{MPa})\end{array}$ & $\begin{array}{c}\text { Modulus of } \\
\text { elasticity }(\mathrm{MPa})\end{array}$ & $\begin{array}{c}\text { Poisson's } \\
\text { ratio }(\mu)\end{array}$ & $\begin{array}{c}\text { Cohesion } \\
(\mathrm{MPa})\end{array}$ & $\begin{array}{c}\text { Angle of } \\
\text { internal friction } \\
\left({ }^{\circ}\right)\end{array}$ \\
\hline & 15.15 & 2.53 & 19.69 & 11065 & 0.30 & 1.78 & 35 \\
\hline
\end{tabular}

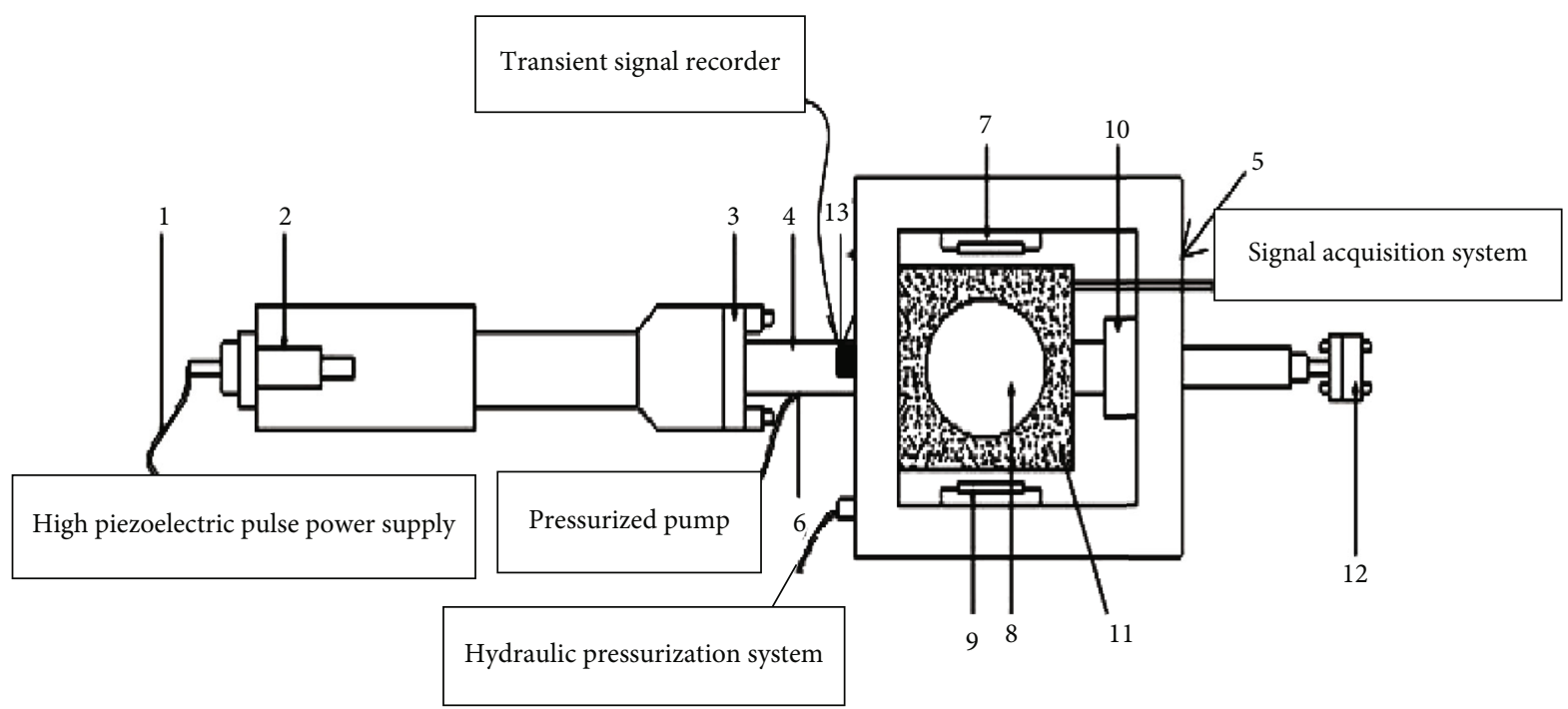

FIGURE 2: Overall system structure of test: (1) coaxial transmission cable, (2) discharge electrode, (3) thick pipe connected with flange, (4) fine transfer pipe, (5) rigid three-axis pressure chamber, (6) high-pressure filling pipe end, (7)-(9) ultra-thin jack, (10) hollow jack, (11) coal sample, (12) end flange, and (13) pressure sensor.

the original effective stress value of coal-rock mass can be obtained according to the derivation formula of Tang [50]:

$$
\sigma_{1}=\frac{1}{3}\left(\sigma_{y}+2 \sigma_{x}\right)-\frac{1}{2}\left(p_{1}-p_{2}\right)
$$

where $\sigma_{\mathrm{x}}$ is the horizontal ground stress, $\mathrm{MPa}, \sigma_{\mathrm{y}}$ is the vertical ground stress, $\mathrm{MPa}, p_{1}$, the atmospheric pressure, is $0.1 \mathrm{MPa}$, and $p_{2}$ is the gas pressure in coal-rock mass, MPa.

The high-voltage electric pulse hydraulic fracturing coalrock mass is cyclically loaded by dynamic and static loads. According to Terzaghi's effective stress principle, the effective stress at a certain moment in the process of electric pulse hydraulic fracturing test can be obtained.

$$
\sigma_{2}=\sigma-p_{2}
$$

where $\sigma$ is the total stress of hydrostatic pressure pulse stress wave. The peak stress of shock wave in the experiment can be taken.

Based on the stress change, the damage variables of electric pulse hydraulic fracturing coal-rock mass were obtained by combining Formulas (2), (4), (5), and (6):

$$
D_{2}=1-\frac{\sigma_{1}}{\sigma_{2}}
$$

TABLE 2: Test schemes for different hydrostatic pressures and different voltages.

\begin{tabular}{lcc}
\hline No. & Hydrostatic pressure/MPa & Voltage $/ \mathrm{kV}$ \\
\hline 1 & 3.0 & 7 \\
2 & 3.0 & 9 \\
3 & 3.0 & 11 \\
4 & 3.0 & 13 \\
5 & 1.0 & 11 \\
6 & 4.0 & 11 \\
7 & 6.0 & 11 \\
8 & 8.0 & 11 \\
\hline
\end{tabular}

Combine Formula (2) with Formula (3), and the following formula was obtained:

$$
E_{2}=E_{1}\left(1-D_{2}\right)
$$

Therefore, the stress-strain constitutive relationship of electric pulse hydraulic fracturing was obtained:

$$
\sigma_{2}=E_{2} \varepsilon_{2}=E_{1}\left(1-D_{2}\right) \varepsilon_{2} .
$$

$E_{1}$ in the constitutive relation (9) is the initial elastic modulus of coal-rock mass, which is relatively easy to measure. Therefore, it is not necessarily to measure the elastic 
Channel/file data

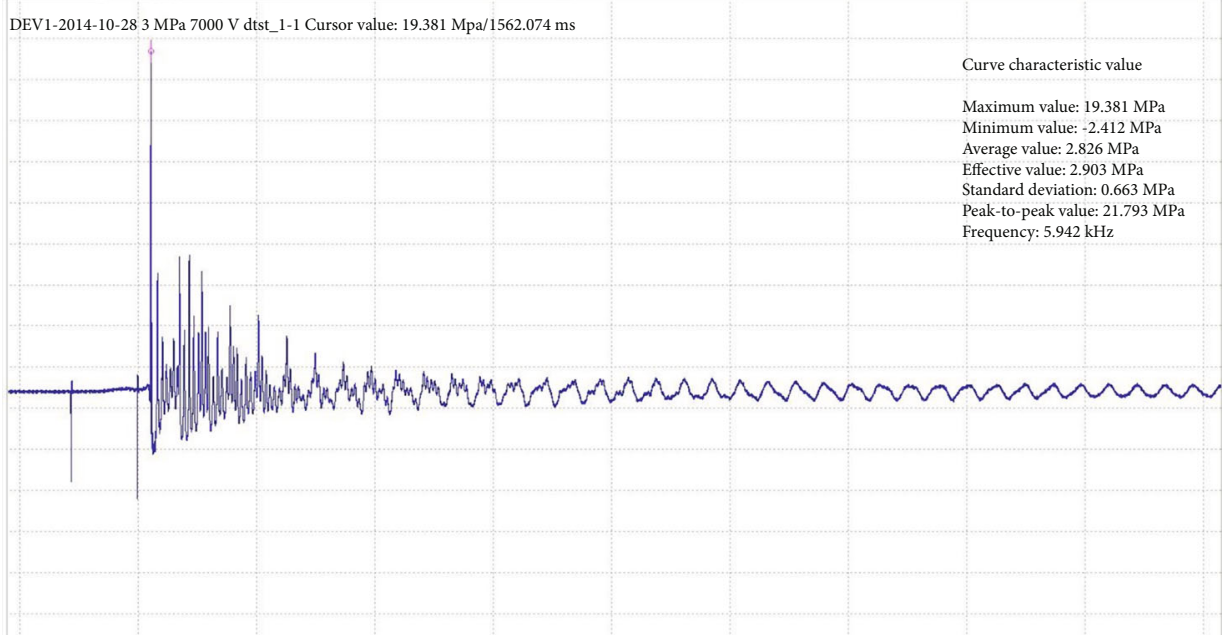

(a) $3 \mathrm{MPa}$ hydrostatic pressure and $7 \mathrm{kV}$ voltage

Channel/file data

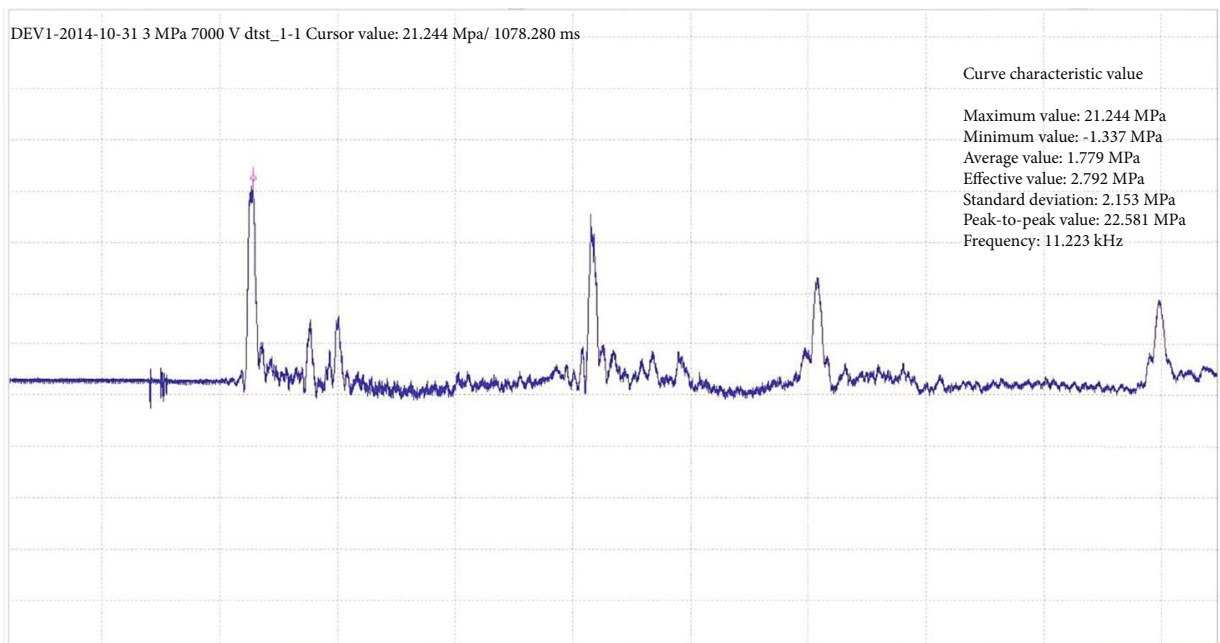

(b) $3 \mathrm{MPa}$ hydrostatic pressure and $9 \mathrm{kV}$ voltage

Channel/file data

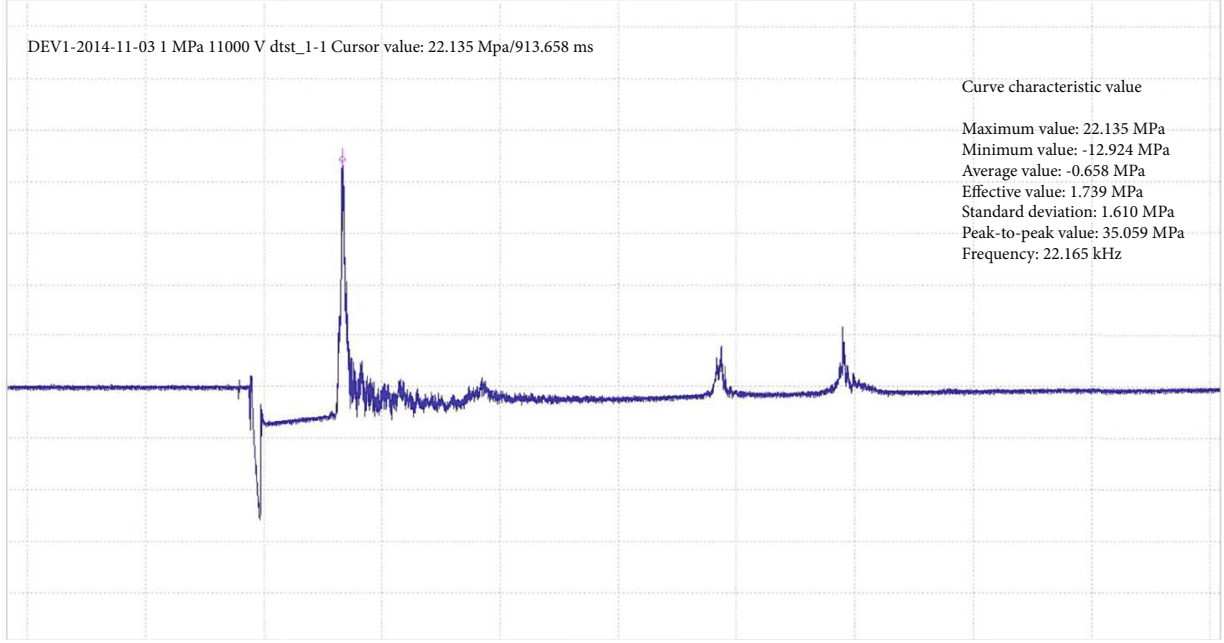

(c) $1 \mathrm{MPa}$ hydrostatic pressure and $11 \mathrm{kV}$ voltage

Figure 3: Continued. 
Channel/file data

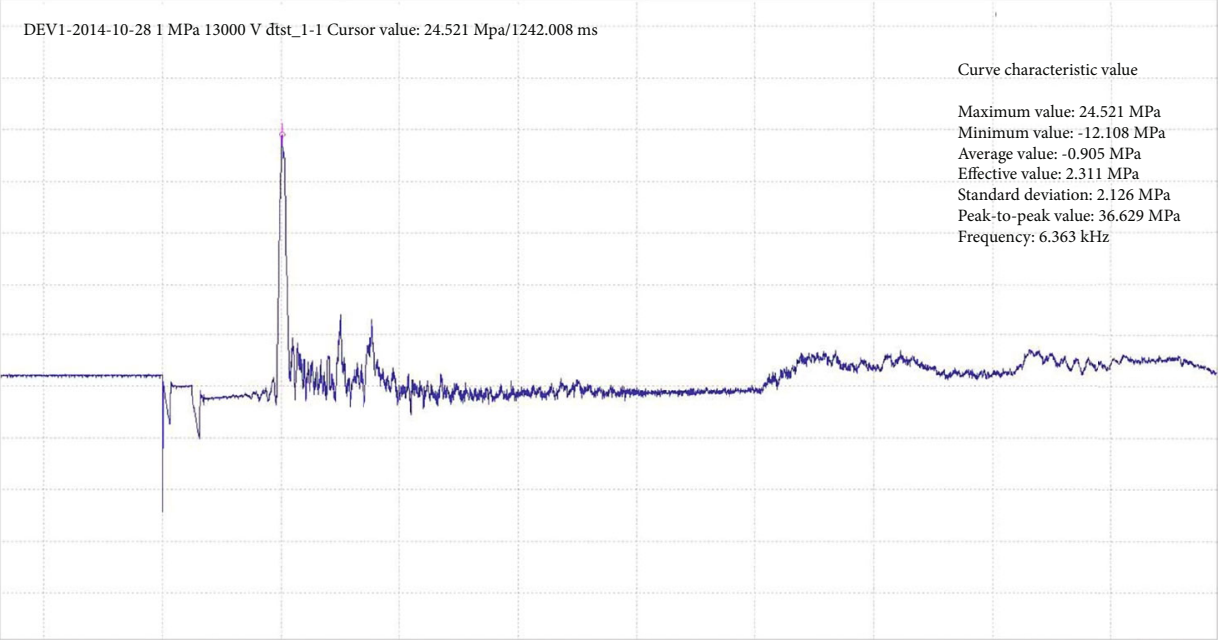

(d) $3 \mathrm{MPa}$ hydrostatic pressure and $13 \mathrm{kV}$ voltage

Channel/file data

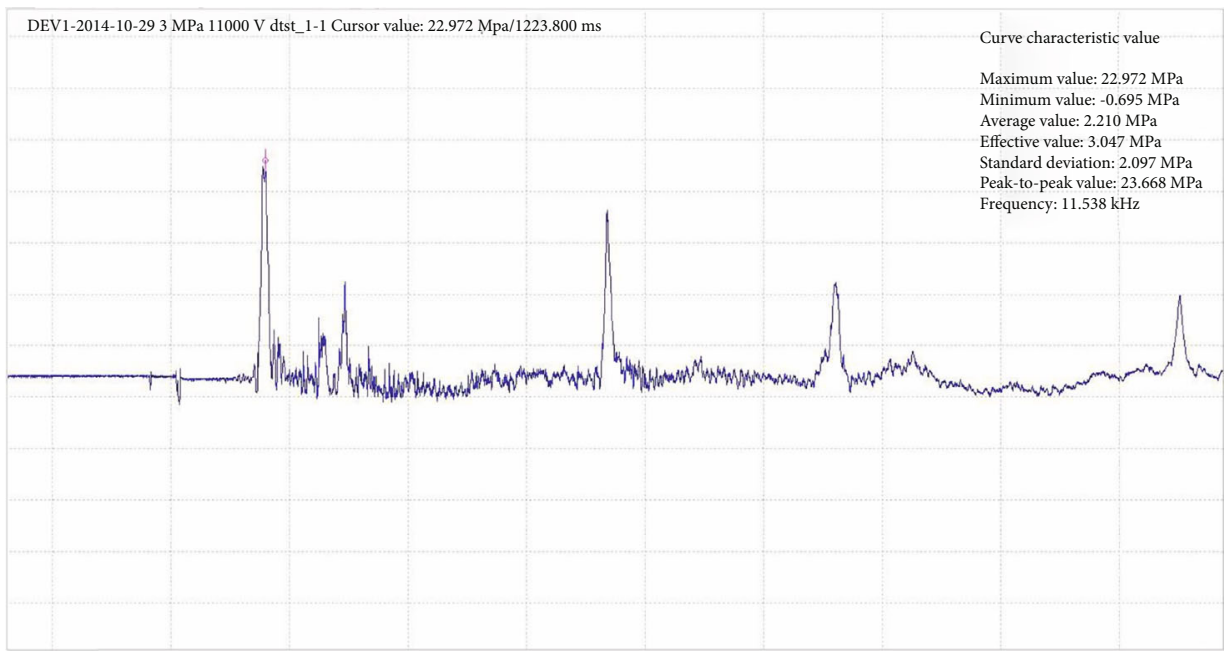

(e) $3 \mathrm{MPa}$ hydrostatic pressure and $11 \mathrm{kV}$ voltage

Channel/file data

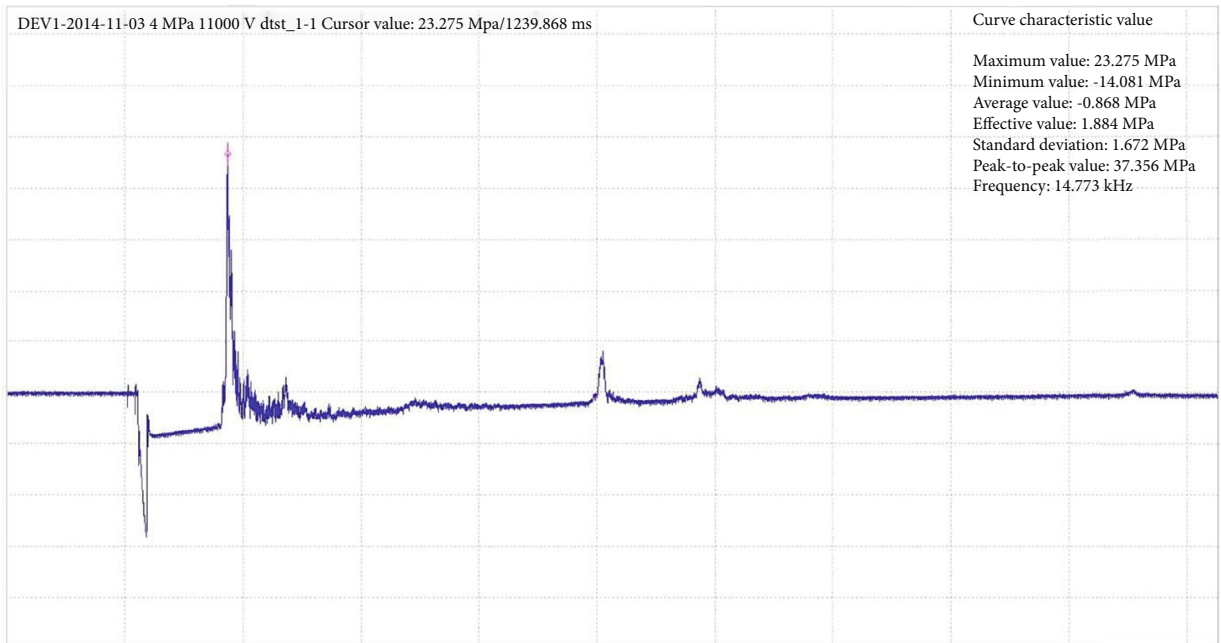

(f) $4 \mathrm{MPa}$ hydrostatic pressure and $11 \mathrm{kV}$ voltage

Figure 3: Continued. 


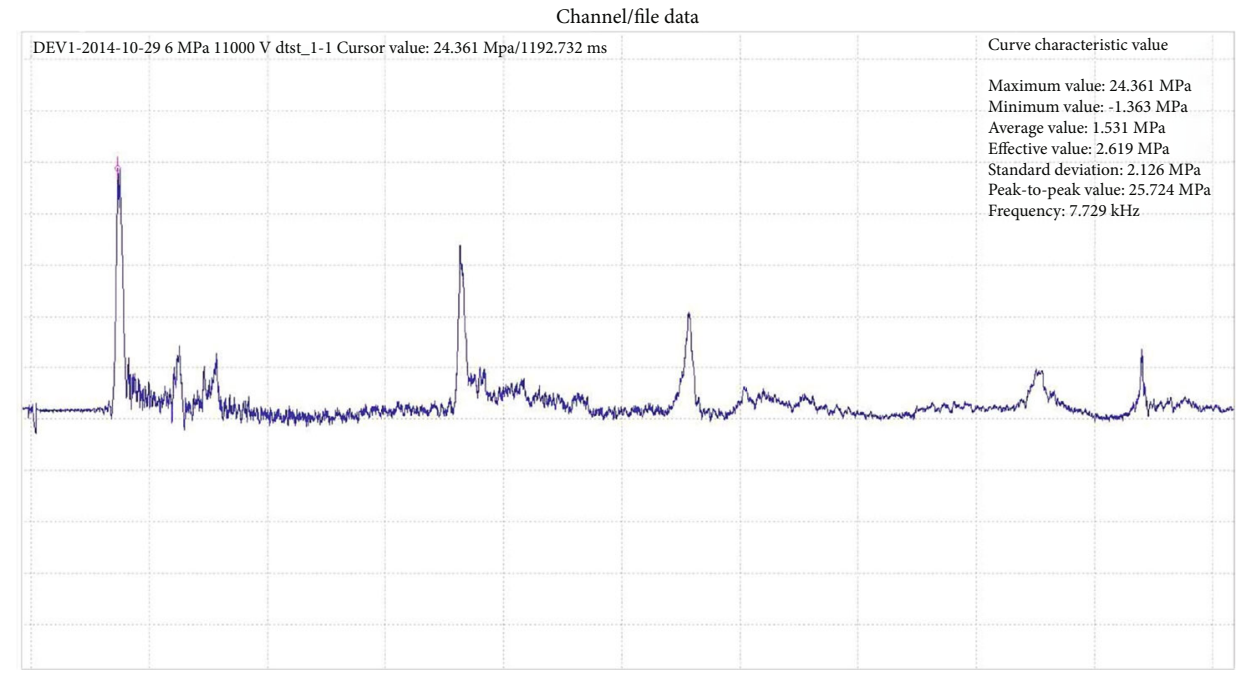

(g) $6 \mathrm{MPa}$ hydrostatic pressure and $11 \mathrm{kV}$ voltage

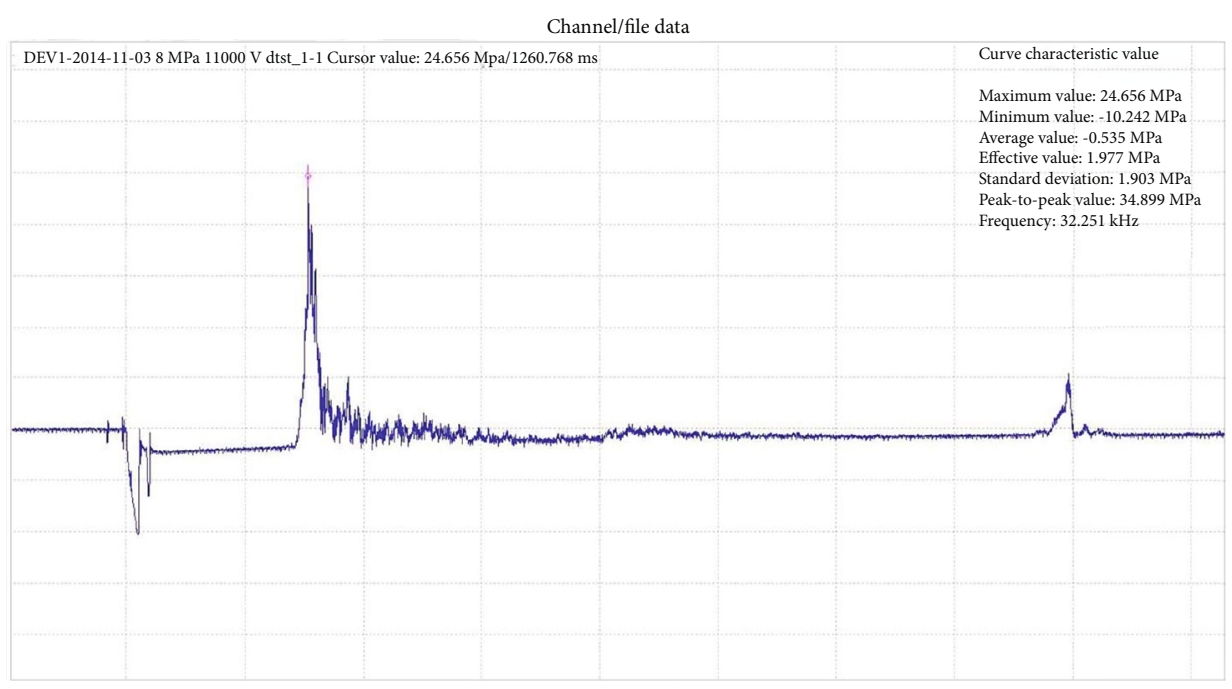

(h) $8 \mathrm{MPa}$ hydrostatic pressure and $11 \mathrm{kV}$ voltage

Figure 3: Peak stress of water shock.

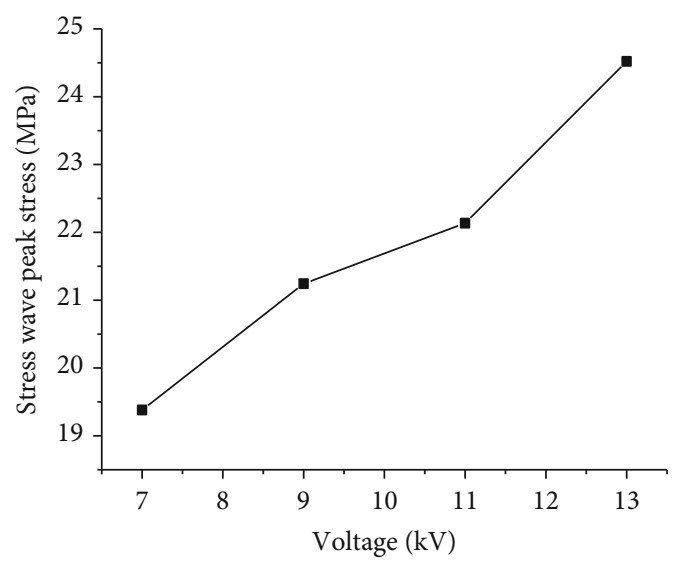

- - Stress wave peak stress (MPa)

(a) Relationship between peak pressure and voltage at $3 \mathrm{MP}$ water pressure

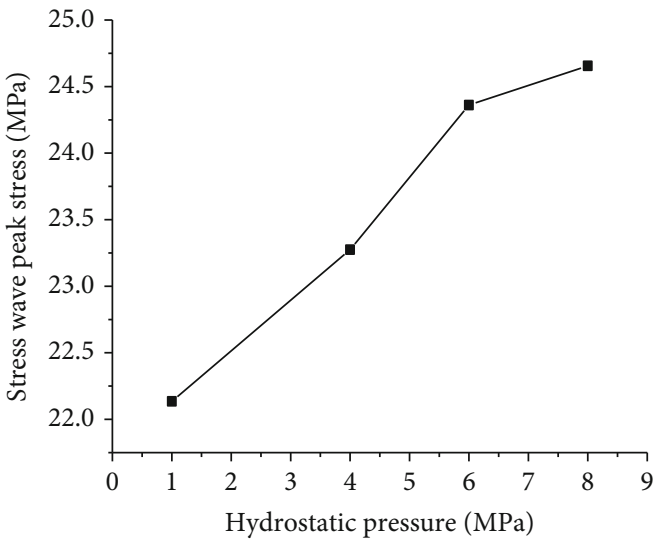

- - Stress wave peak stress (MPa)

(b) Relationship between peak pressure and hydrostatic pressure at $11 \mathrm{kV}$ voltage

FIGURE 4: Peak pressure relationship of water shock. 


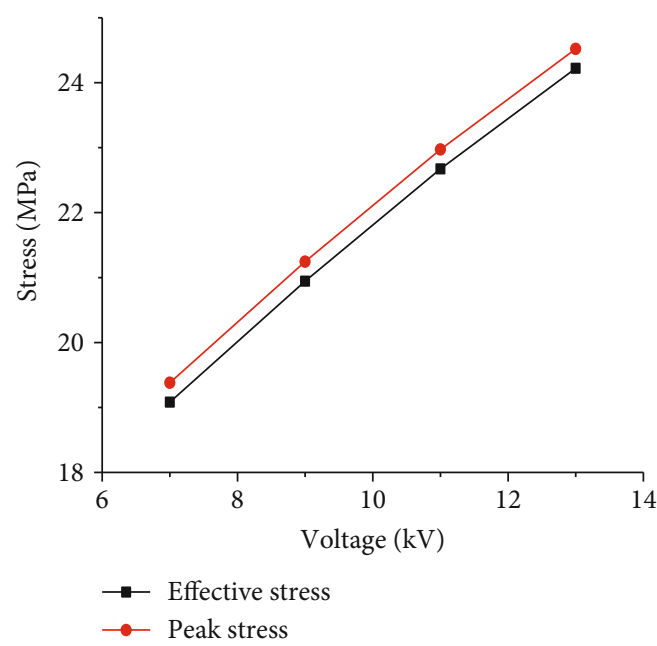

(a) Effective stress at different voltages

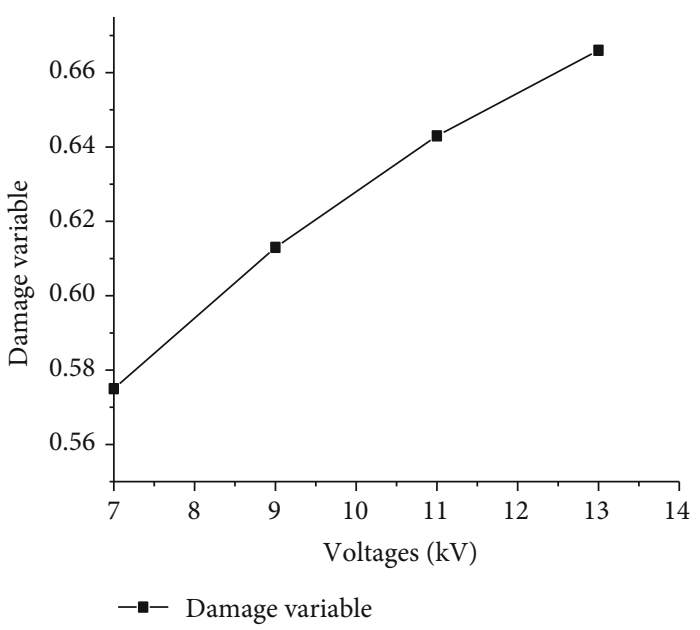

(b) Damage variable at different voltages

Figure 5: Effective stress and damage variable at $3 \mathrm{MPa}$ hydrostatic pressure and different voltages.

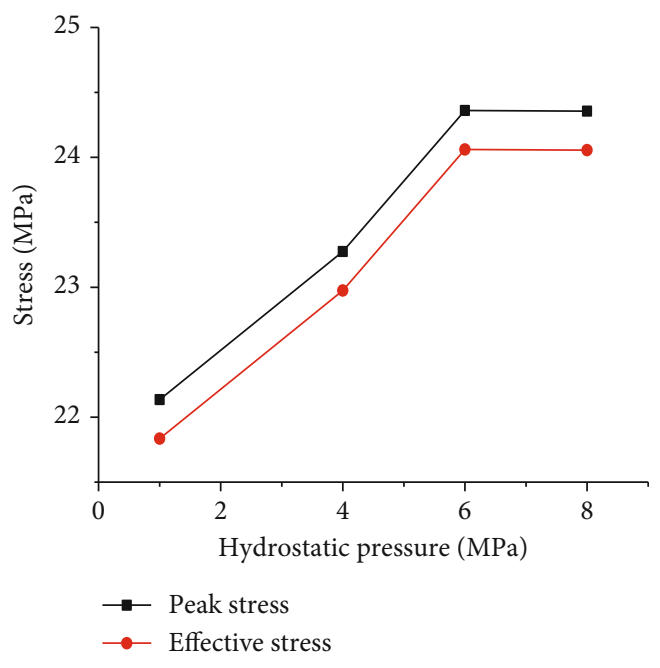

(a) Effective stress at different hydrostatic

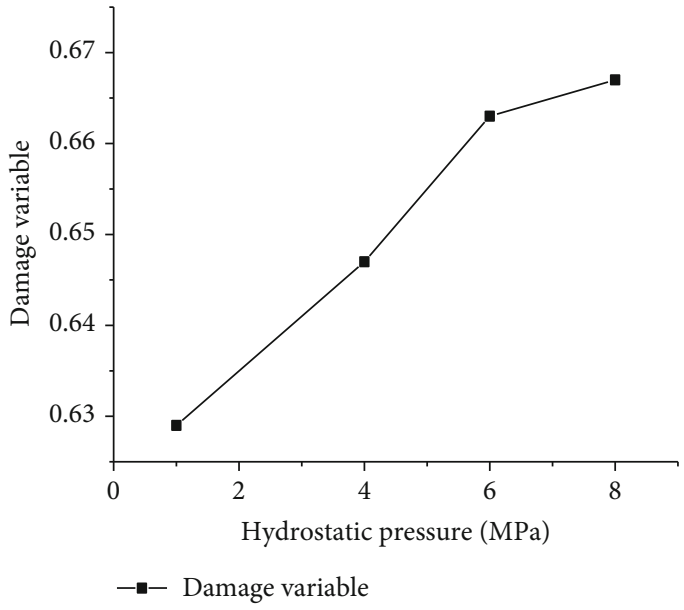

(b) Damage variable at different hydrostatic

FIgURE 6: Effective stress and damage variable at $11 \mathrm{kV}$ discharge voltage and different hydrostatic pressures.

modulus of coal-rock mass after the high-voltage pulse that is not easily measured in the traditional constitutive equation.

\section{Microscopic Damage Test Analysis}

3.1. Preparation of Coal Sample. In order to investigate the stress value generated by the high-voltage electric pulse hydraulic fracturing, the damage expansion of macroscopic cracks of coal-rock mass was quantitatively evaluated, and the high-voltage pulse stress wave test was designed in the laboratory. The coal specimen was the anthracite coal taken from Sihe Coal Mine of Lanyan Company of Shanxi Jincheng Anthracite Coal Mining Group. The coal samples were taken from the 151305 working face which is undisturbed with typical geological units. The average thickness of the coal seam at the working face is $2.36 \mathrm{~m}$, and the tilt angle of the coal seam ranges from $1^{\circ}$ to $14^{\circ}$. The average tilt angle is $4^{\circ}$, and the average gas pressure in the coal seam is $0.29 \mathrm{MPa}$. The coal mass is black with a strip-like structure and metallic luster. The physical and mechanical parameters of coal samples were shown in Table 1.

3.2. Design of Test Scheme. The high-voltage electric pulse hydraulic fracturing system independently developed by the research group was adopted. The test system was shown in Figure 2. The controlled trial of two groups with 8 coal samples was carried out. Coal samples of the first group were loaded into a rigid triaxial pressure chamber. After the filling was completed, the same ground stress was applied to the coal samples. The horizontal confining pressure is $8.66 \mathrm{MPa}$, and the vertical axial pressure is $7.28 \mathrm{MPa}$. After the stress was loaded, $3 \mathrm{MPa}$ hydrostatic pressure was applied to the pipeline and coal samples firstly, and then the high-voltage discharges of $7 \mathrm{kV}, 9 \mathrm{kV}, 11 \mathrm{kV}$, and $13 \mathrm{kV}$ 


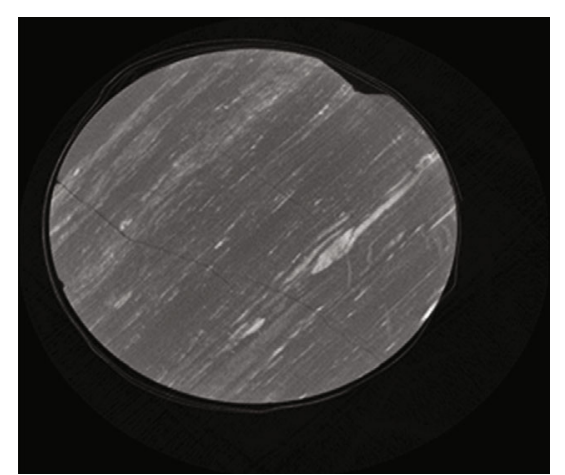

(a) $7 \mathrm{kV} \mathrm{CT} \mathrm{image}$

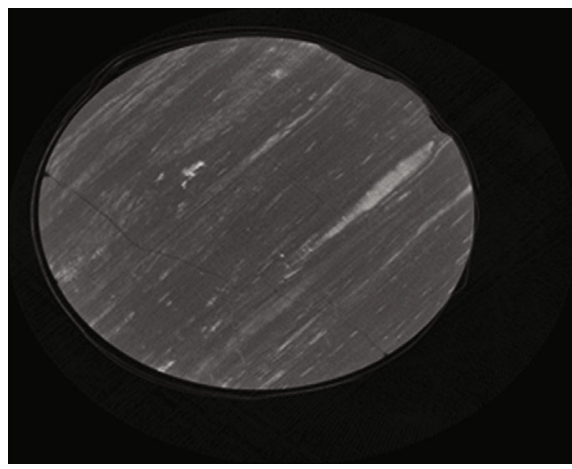

(c) $9 \mathrm{kV}$ CT image

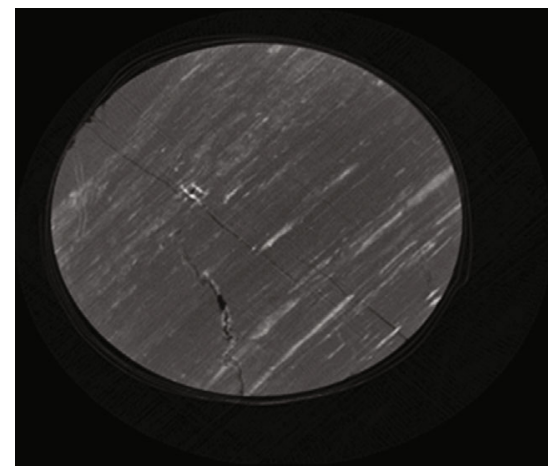

(e) $11 \mathrm{kV}$ CT image

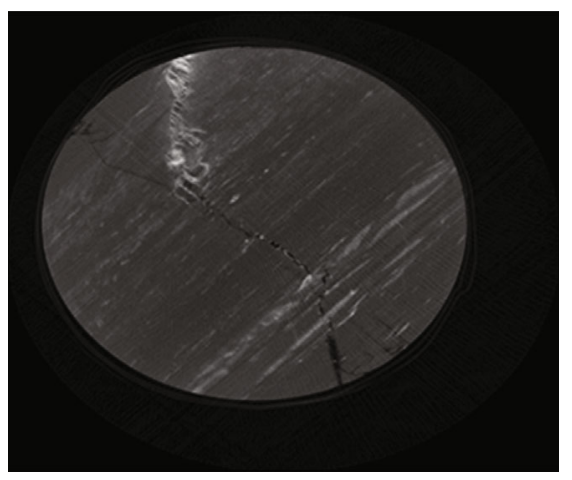

(g) $13 \mathrm{kV}$ CT image

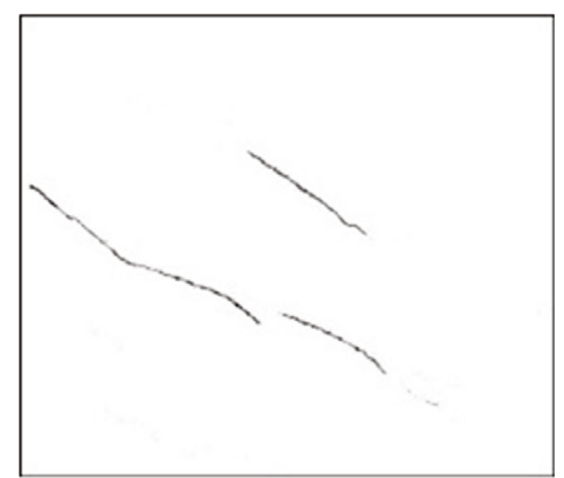

(b) $7 \mathrm{kV}$ binary image

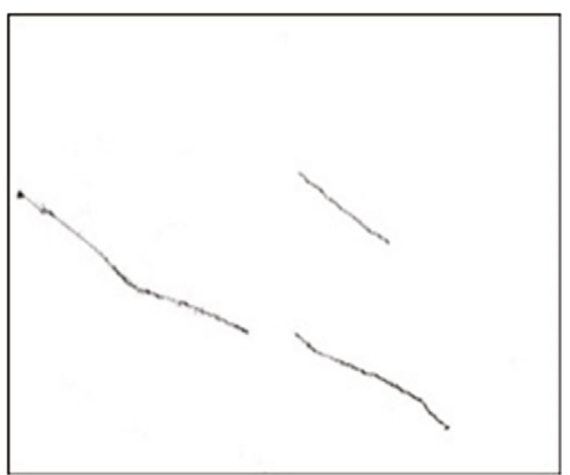

(d) $9 \mathrm{kV}$ binary image

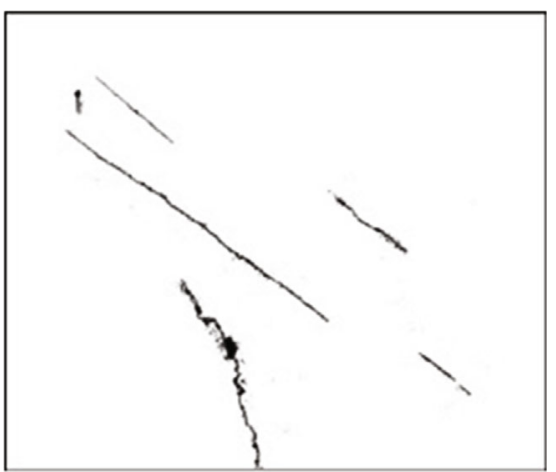

(f) $11 \mathrm{kV}$ binary image

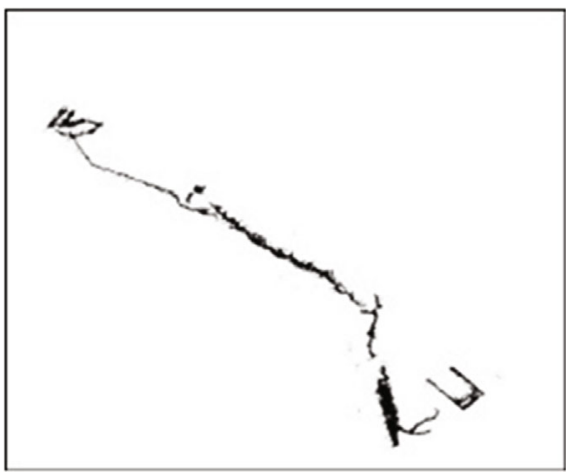

(h) $13 \mathrm{kV}$ binary image

FIgURE 7: Data processing diagram at $3 \mathrm{MPa}$ hydrostatic pressure and different voltages.

were carried out, respectively. The coal sample was taken out after loading. The second group of coal samples was replaced. After the same stress loading was completed, the $11 \mathrm{kV}$ dis- charge voltage was kept unchanged, and the system hydrostatic pressure was changed. The hydrostatic pressures of $1 \mathrm{MPa}, 4 \mathrm{MPa}, 6 \mathrm{MPa}$, and $8 \mathrm{MPa}$ were applied, respectively. 


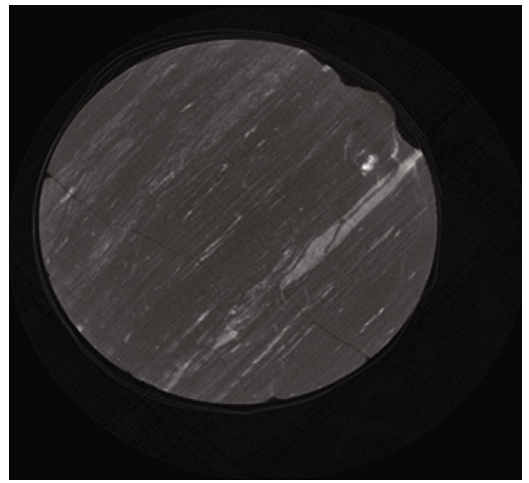

(a) $1 \mathrm{MPa}$ CT image

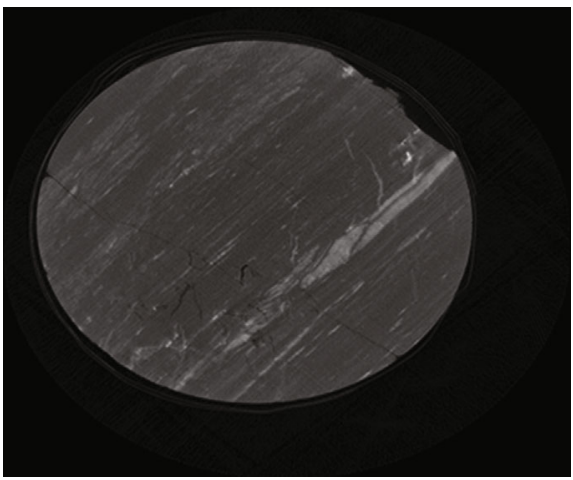

(c) $4 \mathrm{MPa}$ CT image

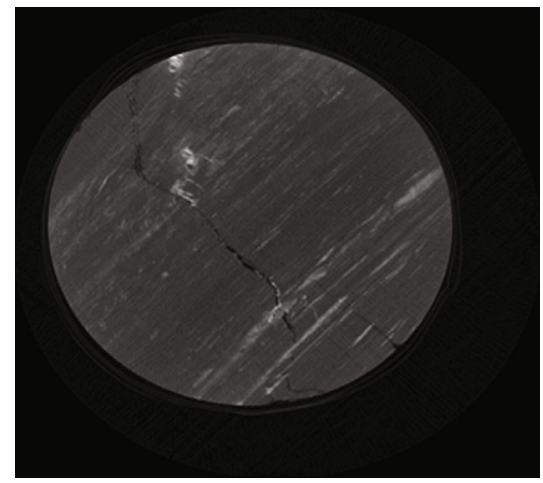

(e) $6 \mathrm{MPa}$ CT image

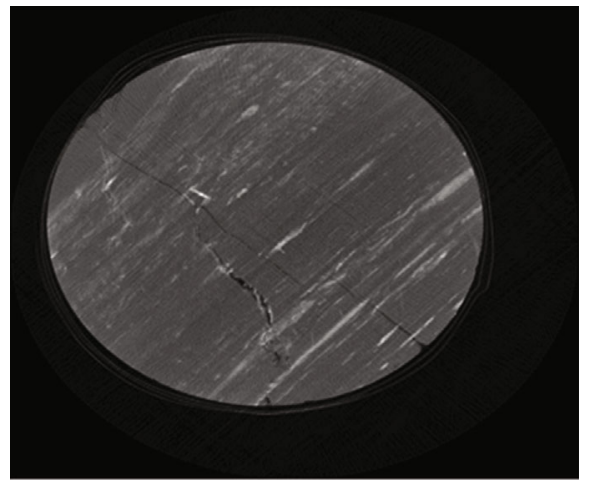

(g) $8 \mathrm{MPa}$ CT image

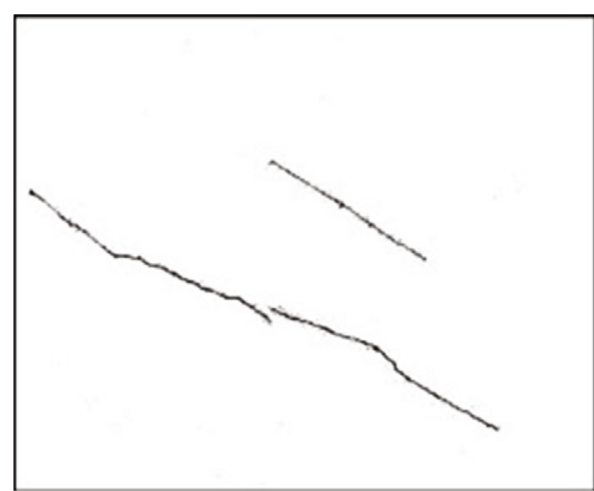

(b) 1 MPa binary image

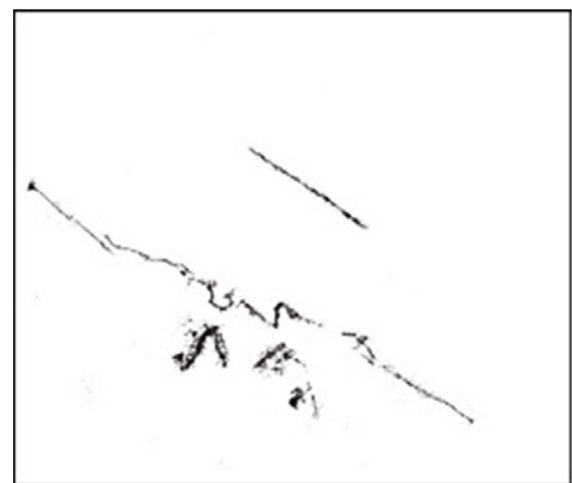

(d) $4 \mathrm{MPa}$ binary image

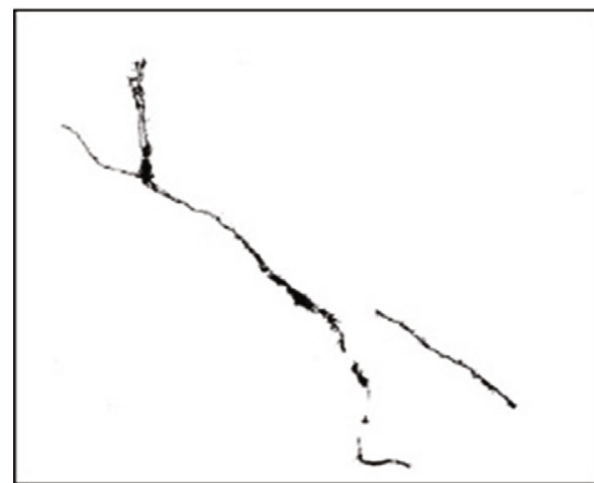

(f) 6 MPa binary image

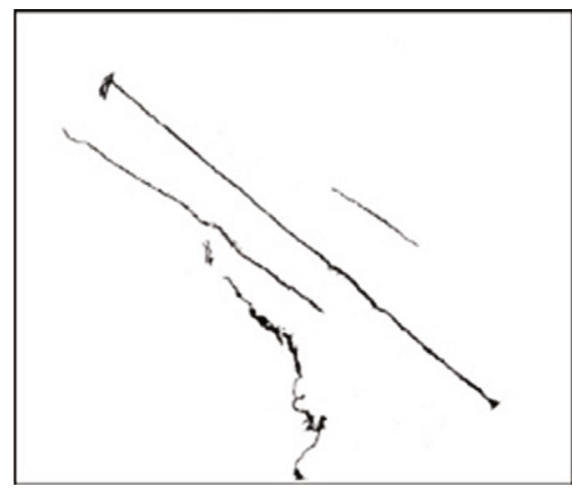

(h) $8 \mathrm{MPa}$ binary image

FIGURE 8: Data processing diagram at $11 \mathrm{kV}$ voltage and different hydrostatic pressures. 
During the test, the waveform and pressure of the stress wave in the water were collected by the high-frequency pressure sensor and the transient signal recorder. After the test, the CT scan detection equipment was used to detect the damage of the coal-rock mass. The specific scheme was shown in Table 2.

3.3. Test and Result Analysis of Stress Wave Peak Pressure. The waveform and pressure of pulse stress wave (water shock wave) were collected and recorded during the experiment by using the high-frequency pressure sensor and the high-speed data-storage device. The results were shown in Figure 3. Then, the relationships of the stress wave peak pressure with the voltage and the water pressure were analyzed, respectively. The results were shown in Figure 4.

As shown in Figures 3 and 4, the maximum peak pressure of water shock after the discharge in water can be measured. After the high-pressure discharge in water, the rising edge of the water shock wave is steep. After reaching the maximum peak value, it decays in an approximate exponential form, and several peaks of the waveform appear. The oscillation decays into a vibration wave (seismic wave) finally. At the same time, it can be found that the maximum peak stress of water shock increases with the increase of voltage when the water pressure is constant. The higher the voltage, the greater the peak stress. When the discharge voltage is constant, the maximum peak stress of water shock also increases with the increase of water pressure, but the peak stress changes less than the amplitude of voltage change.

3.4. Damage Variable Calculation. In order to quantitatively study the microdamage of coal samples under the action of coupling of different water pressures and discharge voltages, the damage variables of coal samples were calculated and analyzed. The ground stress values of coal samples and stress value of coal seam gas were substituted into formula (5), and the measured original effective stress of coal-rock mass was 8.1 $\mathrm{MPa}$. The measured maximum peak stress of water shock wave was brought into formula (6), and the effective stress of coal rock under the action of liquid-electric coupling was obtained, as shown in Figure 5. Then, the damage variable value of coal samples with different liquid-electric parameters was obtained by substituting the effective stress into equation (7). The specific values were shown in Figure 6.

It can be seen from Figures 5 and 6 that under the condition of the constant hydrostatic pressure of $3 \mathrm{MPa}$, the discharge voltage value increases from $7 \mathrm{kV}$ to $13 \mathrm{kV}$; the voltage growth rate is $185.7 \%$, and the damage variable of coal sample increases from 0.575 to 0.666 . The growth variable of the coal sample has a growth rate of $115.8 \%$. The damage variable of the coal sample increases with the increase of discharge voltage. If the discharge voltage is $11 \mathrm{kV}$, the growth rate of hydrostatic pressure is $800 \%$; the damage variable of the coal samples also increases with the increase of hydrostatic pressure, and its increase rate is only $106.1 \%$. Relatively speaking, the voltage increases by about $0.86 \%$, and the damage variable of the coal sample increases by $15.8 \%$. The hydrostatic pressure increases by $700 \%$ while the damage variable of the coal sample only

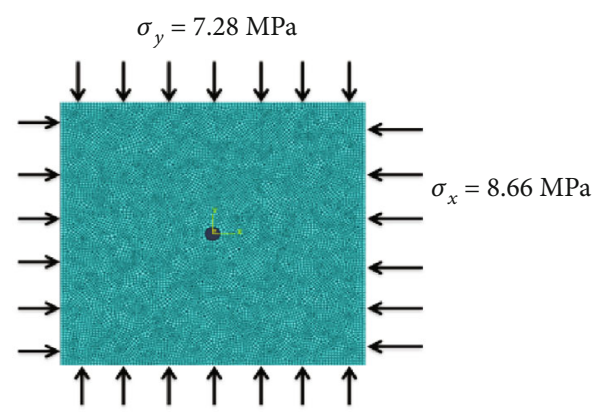

Figure 9: Loading model.

increases by $6.1 \%$. It is indicated that the change of relative hydrostatic pressure and voltage has a more significant influence on the degree of damage of coal-rock mass, and the coal-rock mass has a better cracking effect.

3.5. Analysis of CT Test Results. In order to further verify the microdamage inside the coal-rock mass, after the highvoltage electric pulse hydraulic fracturing of the coal-rock specimen, the tested coal-rock mass was sampled and analyzed, and then the sample was damaged by the CT test equipment. The CT scanning results were binarized by means of the Particle and Crack Analysis System (PCAS) developed by Nanjing University in which the black is the crack part and the white is the coal mass. The CT scanning results and the corresponding binary images obtained after PCAS treatment were shown in Figures 7 and 8 (the drilled specimens can be constructed with more than 1500 layers after scanning; only representative layers are selected, and the remaining layers are similar).

It can be seen from Figure 7 that after the CT scanning detection, binarization treatment, and $7 \mathrm{kV}$ and $9 \mathrm{kV}$ discharge under the condition of maintaining the hydrostatic pressure of $3 \mathrm{MPa}$, after, three irregular and intermittent cracks occur in the coal slice scanning section, and the length and the opening degree of cracks are small. Under the $11 \mathrm{kV}$ discharge condition, five intermittent cracks occur in the coal seam scanning slice, and the number, length, and damage expansion degree of cracks increase. When the voltage increases to $13 \mathrm{kV}$, the penetration, opening degree, length, and roughness of cracks increase obviously, and the damage expansion degree is intensified. In general, under the condition of maintaining the hydrostatic pressure of $3 \mathrm{MPa}$, with the increase of discharge voltage, the number, total length, expansion degree, penetration, damage area, and crack rate of coal-rock specimens increase linearly. The trend indicates that the damage degree of coal rock increases with the increase of discharge voltage.

It can be seen from Figure 8 that when the discharge voltage is $11 \mathrm{kV}$ and the hydrostatic pressure is $1 \mathrm{MPa}$, three intermittent cracks occur in the coal slice scanning section; when the hydrostatic pressure is $4 \mathrm{MPa}$, the crack penetrates to form the main crack, and its roughness and opening degree increase. Many short and irregular cracks occur around the main crack; when the hydrostatic pressure is $6 \mathrm{MPa}$, the main crack branches, and its length, opening 
TABLE 3: Mechanical parameters of coal-rock mass.

\begin{tabular}{lccccc}
\hline $\begin{array}{l}\text { Density of natural } \\
\left(\mathrm{kg} / \mathrm{m}^{3}\right)\end{array}$ & $\begin{array}{c}\text { Compressive strength } \\
(\mathrm{MPa})\end{array}$ & $\begin{array}{c}\text { Tensile strength } \\
(\mathrm{MPa})\end{array}$ & $\begin{array}{c}\text { Modulus of elasticity } \\
(\mathrm{GPa})\end{array}$ & $\begin{array}{c}\text { Poisson's ratio } \\
(\mu)\end{array}$ & $\begin{array}{c}\text { Angle of internal } \\
\text { friction }\left({ }^{\circ}\right)\end{array}$ \\
\hline 1515 & 19.69 & 2.53 & 11.065 & 0.3 & 35 \\
\hline
\end{tabular}

degree, and roughness further increase; when the pressure is increased to $8 \mathrm{MPa}$, three main cracks are generated. One has a long length, and another one has a large opening degree. The crack rate of coal-rock specimens further increases.

Compared Figure 7 with Figure 8, it can be seen that the damage degree of coal-rock specimens is directly related to the change of hydrostatic pressure and discharge voltage, but the change of discharge pressure has a greater influence on the damage degree and crack rate of coal-rock specimens than that of hydrostatic pressure. It is consistent with the evaluation results of coal-rock damage caused by the macroscopic damage variables of coal-rock mass derived from the interaction of effective stress.

\section{Microdamage Numerical Analysis}

In order to further verify the damage model, it is more comprehensive to evaluate the damage degree of high-pressure electric pulse hydraulic fracturing technique on the coalrock mass quantitatively and to further deduct the damage variable of coal-rock mass. The damage variable was derived from the change of the effective bearing area of coal-rock mass by the numerical simulation, and the damage degree and expansion of microcrack were further evaluated. According to the definition of damage variable, Formula (10) was obtained:

$$
D_{2}=\frac{A_{1}-A_{2}}{A_{1}}=\frac{A_{D}}{A_{1}}
$$

where $A_{1}$ and $A_{2}$ have the same meaning as those in Formula (2); $A_{D}$ is the damage area of coal-rock under the electrohydraulic coupling.

The change of bearing area of the microjoint unit of the coal-rock mass was measured by the high-voltage electric pulse load. The change of damage variable was obtained by Formula (10), and the damage morphological change of coal-rock mass was further characterized.

4.1. Establishment of the Numerical Model. The coal sample of 151305 working face in Sihe Coal Mine was taken as the simulation object. The ABAQUS/XFEM module was used to establish the numerical model under the coupling effect of "solid-liquid-electricity." The model size is $2 \mathrm{~m} \times 2 \mathrm{~m}$, and the length of the preset single original crack is $0.1 \mathrm{~cm}$. The length of the cell is $2 \mathrm{~cm}$. Therefore, the original effective bearing area of the unit section is $4 \times 10^{-4} \mathrm{~m}^{2} .8 .66 \mathrm{MPa}$ and 7.28 MPa ground stress were applied in the horizontal direction and in the vertical direction, respectively. The model was shown in Figure 9. The model parameters were shown in Tables 3 and 4 .
TABle 4: Physical parameters of coal-rock mass.

\begin{tabular}{lcccc}
\hline $\begin{array}{l}\text { Permeability } \\
\text { coefficient } \\
(\mathrm{m} / \mathrm{s})\end{array}$ & $\begin{array}{c}\text { Filtration } \\
\text { coefficient } \\
\text { (m/pas) }\end{array}$ & $\begin{array}{c}\text { Fracturing } \\
\text { fluid } \\
\text { viscosity } \\
\text { (pas) }\end{array}$ & $\begin{array}{c}\text { Peak } \\
\text { displacement } \\
\left(\mathrm{m}^{2} / \mathrm{s}\right)\end{array}$ & $\begin{array}{c}\text { Natural } \\
\text { fracture } \\
\text { angle }\left(^{\circ}\right)\end{array}$ \\
\hline $1 \mathrm{e}-7$ & $1 \mathrm{e}-14$ & 0.001 & 0.002 & 0 \\
\hline
\end{tabular}

4.2. Damage Degree of Coal Rock at $3 \mathrm{MPa}$ Hydrostatic Pressure and Different Voltages. As shown in Figure 10, $7 \mathrm{kV}$ high-voltage pulse discharge was performed in $3 \mathrm{MPa}$ hydrostatic pressure. The maximum opening degree of cracks in coal-rock mass is $1.21 \times 10^{-2} \mathrm{~m}$, and the maximum damage area of the crack unit is $1.21 \times 10^{-2} \times 2 \times 10^{-2}=$ $2.42 \times 10^{-4} \mathrm{~m}^{2}$ (where $2 \times 10^{-2}$ is the original length of cell). The original effective bearing area of the unit section is $4 \times$ $10^{-4} \mathrm{~m}^{2}$. The damage variable is 0.605 by substituting the above data into Formula (10); the effective bearing area of the cell after loading is $2 \times 10^{-2} \times 2 \times 10^{-2}-2.42 \times 10^{-4}=$ $1.68 \times 10^{-4} \mathrm{~m}^{2}$. At the same time, under the condition of constant hydrostatic pressure, the effective bearing area and damage variable at other discharge voltages can be obtained, as shown in Figure 11. It can be seen from Figure 11 that with the increase of electric pulse load, the effective bearing area of coal-rock mass decreases, and the damaged area and damage variable increase. It is indicated that with the increase of discharge voltage and stress peak generated in the water, the damage degree gradually increases.

4.3. Damage Degree of Coal-Rock Mass at $11 \mathrm{kV}$ Voltage and Different Hydrostatic Pressures. As shown in Figure 12, $11 \mathrm{kV}$ high-voltage pulse discharge was performed in hydrostatic pressure of $1 \mathrm{MPa}$. The maximum opening degree of cracks in coal-rock mass is $1.39 \times 10^{-2}$ $\mathrm{m}$, and the maximum damage area of the crack unit is $1.39 \times 10^{-2} \times 2 \times 10^{-2}=2.78 \times 10^{-4} \times \mathrm{m}^{2}$ (where $2 \times 10^{-2}$ is the original length of cell). The original effective bearing area of the unit section is $4 \times 10^{-4} \mathrm{~m}^{2}$. The above data can be substituted into the Formula (10) to obtain the damage variable of 0.695 . At the same time, the effective bearing area of the loading cell is $2 \times 10^{-2} \times 2 \times 10^{-2}-2.78 \times 10^{-4}=1.22 \times$ $10^{-4} \mathrm{~m}^{2}$. When the discharge voltage is constant, the effective bearing area and damage variable at other hydrostatic pressures can be calculated, as shown in Figure 13. It can be seen from Figure 13 when the discharge voltage remains unchanged, with the increase of hydrostatic pressure, the effective bearing area of coal-rock mass decreases, and the damaged area and damage variable increase. It is indicated that with the increase of discharge voltage and stress peak generated in the water, the damage degree gradually increases. 


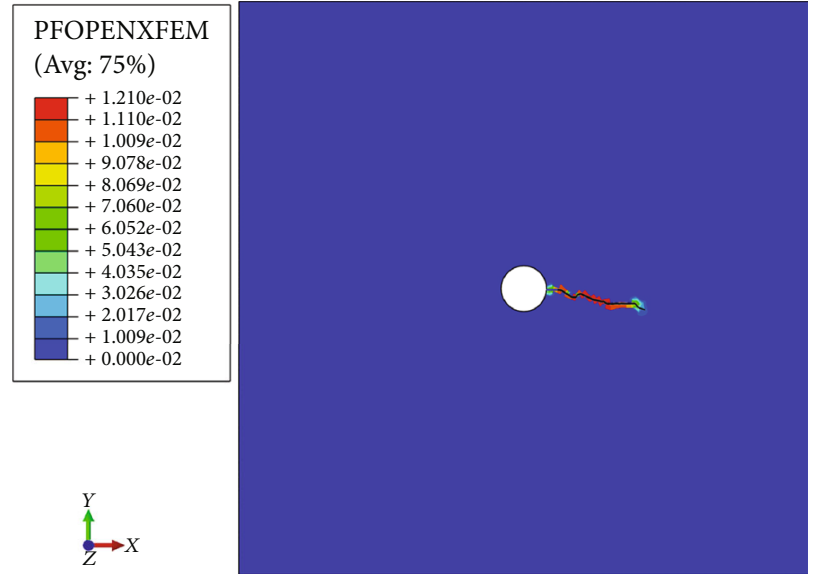

(a) $7 \mathrm{kV}$ voltages

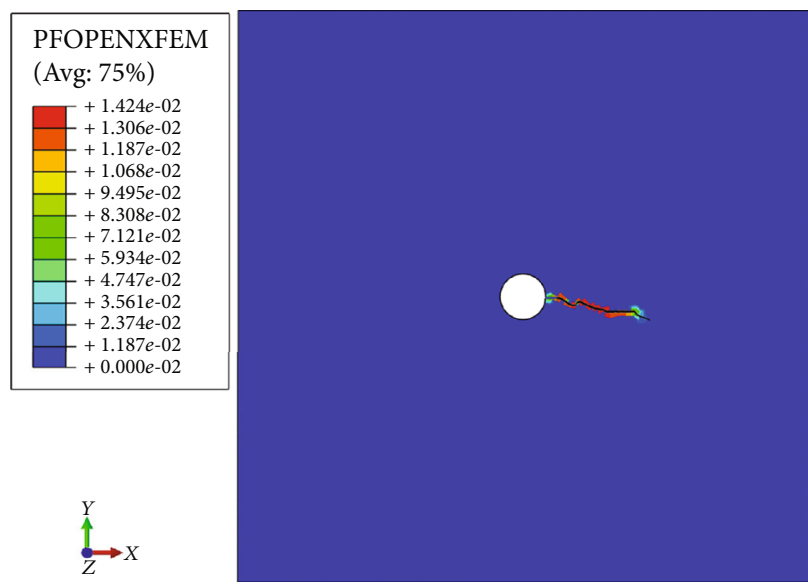

(c) $11 \mathrm{kV}$ voltages

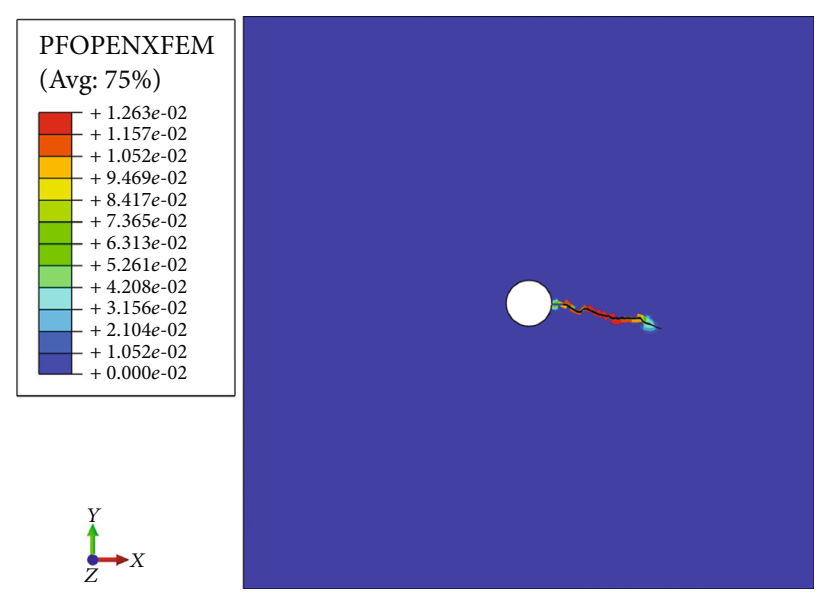

(b) $9 \mathrm{kV}$ voltages

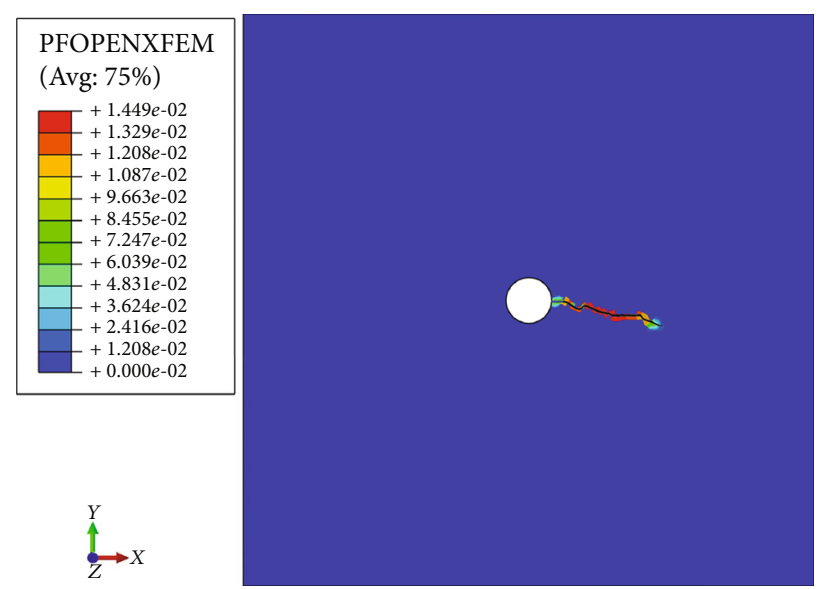

(d) $13 \mathrm{kV}$ voltages

FiguRE 10: Opening degree of crack at $3 \mathrm{MPa}$ hydrostatic pressure and different voltages.

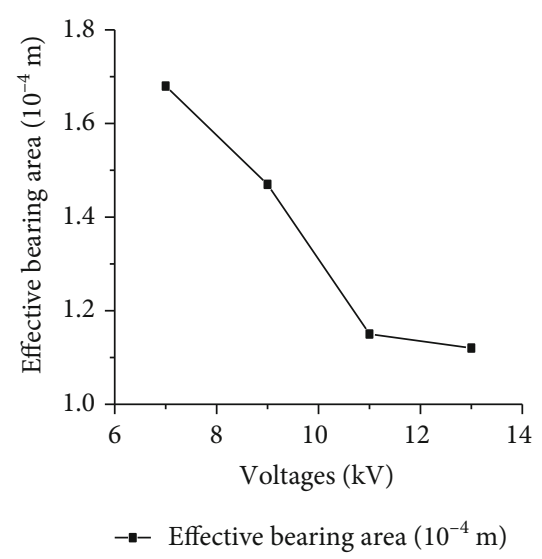

(a) Effective bearing area of coal-rock mass

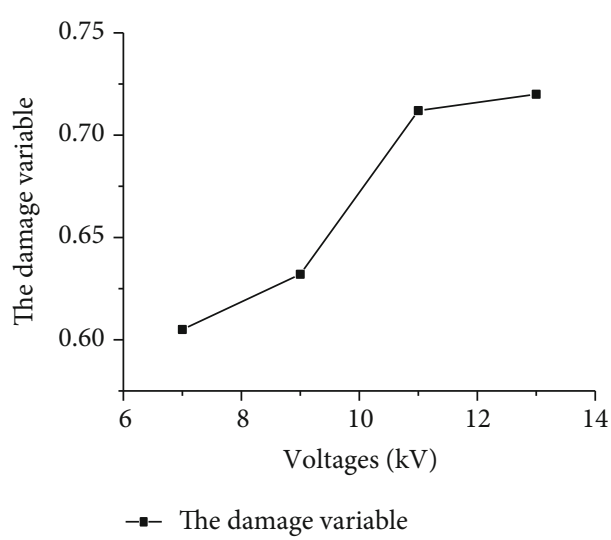

(b) Damage variable of coal-rock mass

FIgURE 11: Variation of the effective bearing area and damage variable at $3 \mathrm{MPa}$ hydrostatic pressure and different discharge voltages.

\section{Discussion}

When the high pressure is discharged in pressurized water, the stress wave generated by the electric explosion can make the defects crack, expand, and penetrate the coal-rock mass, such as voids and microcracks. Therefore, it is especially important to study the fracture and expansion behaviors of microcracks. However, how to test and evaluate the initiation, expansion behaviors, and effects of microcracks accurately and quantitatively has always been a problem that draws scholars' attention. 


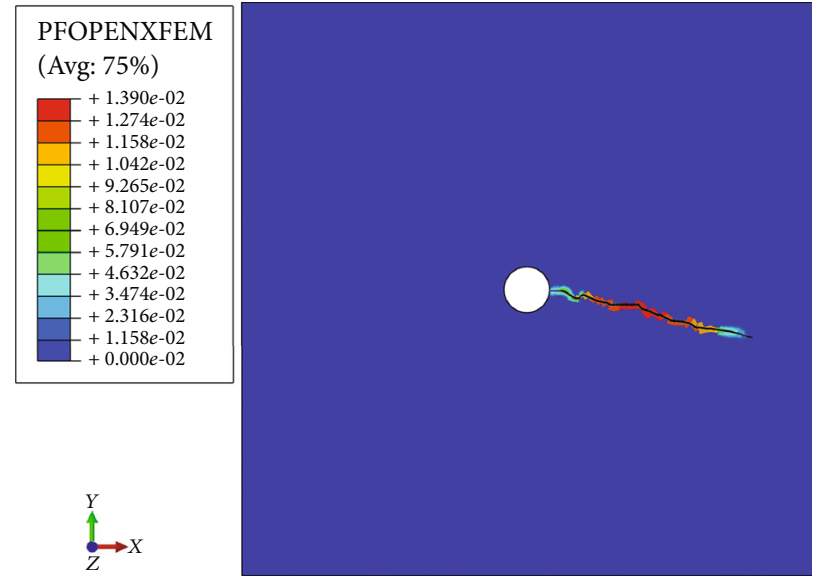

(a) $1 \mathrm{MPa}$ hydrostatic pressure

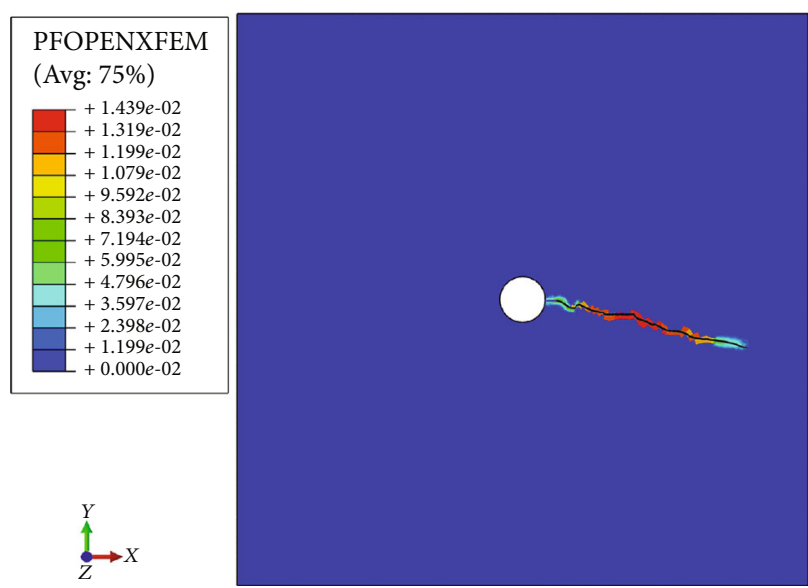

(c) $6 \mathrm{MPa}$ hydrostatic pressure

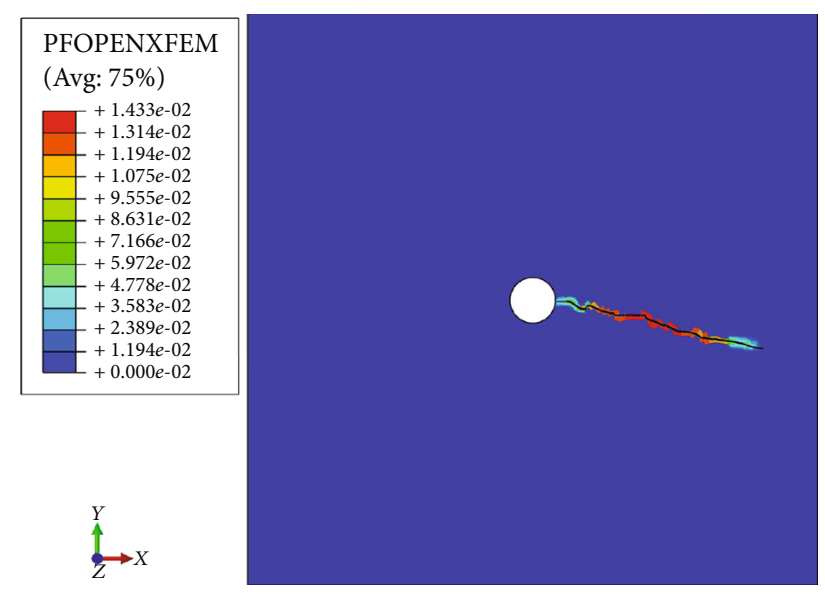

(b) $4 \mathrm{MPa}$ hydrostatic pressure

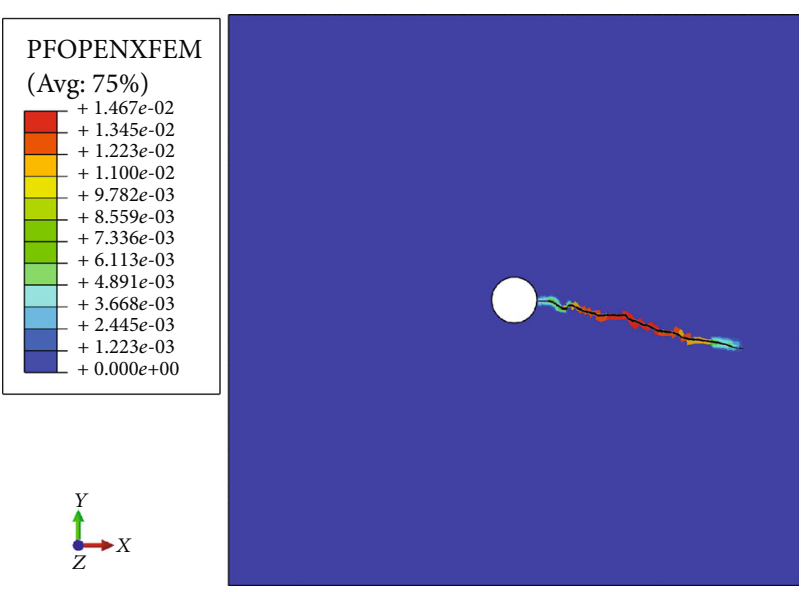

(d) $8 \mathrm{MPa}$ hydrostatic pressure

FIgURE 12: Opening degree of crack at $11 \mathrm{kV}$ voltage and different hydrostatic pressures.

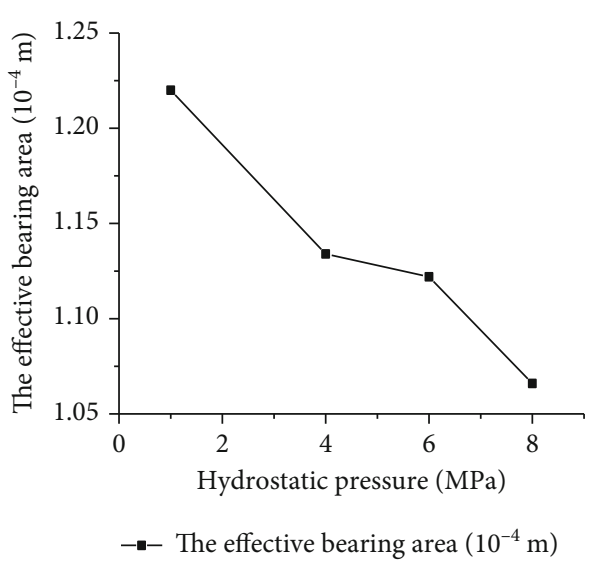

(a) Effective bearing area of coal-rock mass

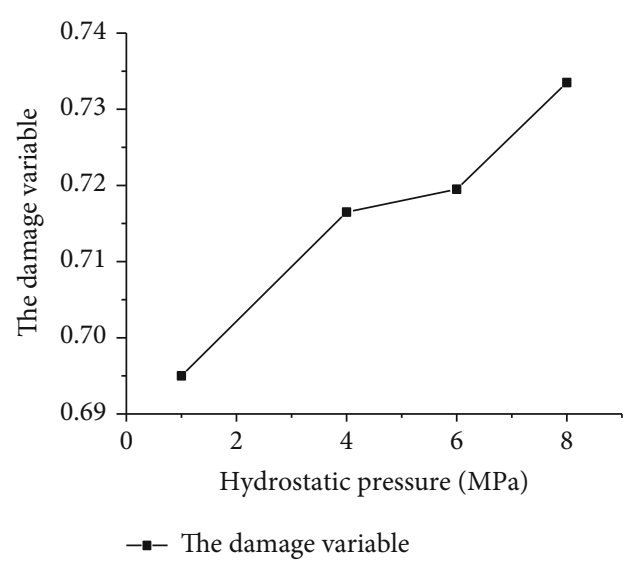

(b) Damage variable of coal -rock mass

FIGURE 13: Variation of the effective bearing area and damage variables of coal-rock mass at $11 \mathrm{kV}$ voltage and different hydrostatic pressures.

From the above test and numerical simulation, combined with the observation results of CT scanning, the microscopic damage of coal-rock mass was accurately evaluated by calculating the damage variable of coal-rock mass. Then, the macroscopic damage behavior of the coal-rock mass structure was revealed. Compared with the damage variable at the same loading, the comparison diagram of damage variables was obtained, as shown in Figure 14.

It can be seen from Figure 14 that the stress-based damage variable obtained by the experiment and the damage 


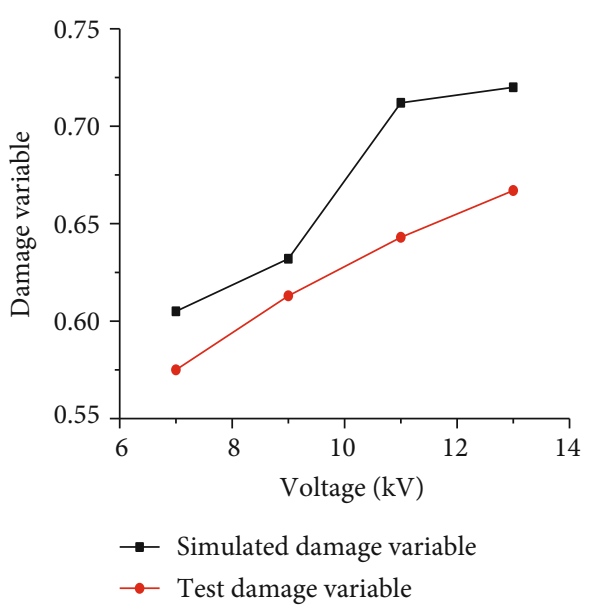

(a) Damage variable of coal-rock mass at $3 \mathrm{MPa}$ hydrostatic pressure and different voltages

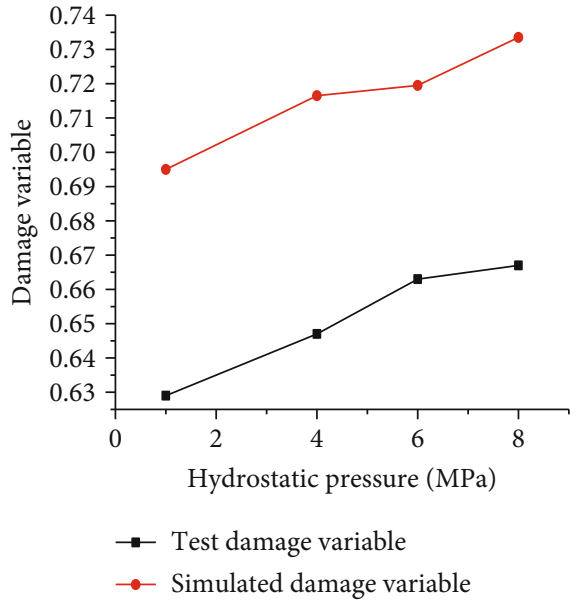

(b) Damage variable of coal-rock mass at $11 \mathrm{kV}$ voltage and different hydrostatic pressures

Figure 14: Comparison of damage variables.

variable based on the damaged area obtained by numerical simulation has almost the same change trend at the same loading, and their values are not much different. This is mainly because the isotropic nature of material parameters during the simulation causes small changes of values in the test and simulation. These two research methods confirm each other, which indicates that the damage variable of coal-rock mass can reflect the internal microdamage evolution, the expansion, and the extension process of macrocrack. Therefore, the damage degree of coal-rock mass can be quantitatively characterized.

Based on the relationships between the Newtonian fluid mechanics and the damage mechanics, and between the damage evolution characteristics and the macrocrack occurrence, the damage model was established by using the change of effective stress, damage area, and damage variable to better characterize the variation of effective stress, effective bearing area, and damage variable of coal-rock mass under the action electric pulse hydraulic fracturing electrohydraulic coupling effect. The damage evolution of coal-rock mass materials from the initial cracking to complete cracking under the action of electrohydraulic coupling was revealed, and the macrodamage degree of coal-rock mass was quantitatively characterized, which provides an important way and method for the application of engineering practice.

Despite the establishment of damage variables and damage models based on the effective stress and effective bearing area of coal-rock mass, the damage degree of coal-rock mass under the action of electrohydraulic coupling was quantitatively evaluated by the numerical simulation and experiment, but the current research is still in the preliminary exploration stage. Some difficult issues remain to be further studied.

(1) Due to the limitations of the detection technique, the damage width and area of microcracks in coal-rock mass at this stage cannot be quantified by test and detection. At this stage, only the numerical simulation can be used to derive the results
(2) The quantitative test for the high-voltage electric pulse hydraulic fracturing is still in the research stage of single crack expansion, and the research on the composite crack change and mutual influence is slightly insufficient

(3) The coal-rock mass expansion models adopted in most studies at home and abroad are based on the isotropic assumption of material, but in the engineering practice process, the coal-rock material and crack expansion are anisotropic. Therefore, the research on the anisotropy of materials and its influence on crack fracture and expansion should be strengthened in the future

(4) Due to the nonuniformity and permeability of the coal-rock structure, the existing numerical simulation methods for high-voltage electric pulse hydraulic fracturing still have certain defects, such as difficulties in handling the multicrack expansion and acquiring the calculation parameters required by prefabrication cracks or numerical simulation. At the same time, the factors affecting the hydraulic crack expansion of high-voltage electric pulse in coal-rock mass need to be further studied systematically

\section{Conclusion}

(1) Based on the correlation between macroscopic defects and damage evolution of coal-rock mass, a dynamic damage constitutive model of coal-rock mass was constructed. The correctness of the model under the action of electric-liquid coupling was verified by experiments and numerical calculations

(2) The effective bearing area, effective stress, and damage variable can be used to evaluate the damage degree of macroscopic cracks of coal-rock under the action of electric-liquid coupling quantitatively and effectively, thus revealing the damage law of coal- 
rock mass under the coupling effect of hydrostatic pressure and electric pulse load

(3) Through tests and numerical simulations, it can be seen that compared with the change of water pressure, the change of voltage has more influence on the damage of coal-rock mass during the highvoltage pulse hydraulic fracturing process. The change of damage variable of coal-rock mass is more significant

(4) With the increase of electric pulse load, the effective bearing area of the coal-rock bearing unit decreases, and its damage variable increases. The damage variable is positively correlated with the pulse load and negatively correlated with the effective bearing area of the unit. The damage variables obtained in the experiment are consistent with the calculation values of numerical simulation

\section{Data Availability}

The data used to support the findings of this study are included within the article.

\section{Conflicts of Interest}

The author(s) declare(s) that they have no conflicts of interest.

\section{Acknowledgments}

The study was supported by the Inner Mongolia Natural Science Foundation [grant no. 2020LH05018], Inner Mongolia Natural Science Foundation [grant no. 2019MS05053], and Shanxi Natural Science Foundation [grant no. 201701D22111223].

\section{References}

[1] Z. Yang and Z. Cai, "Into the source to find oil: the connotation and prospect of source rock oil and gas," Petroleum Exploration and Development, no. 3, pp. 1-12, 2019.

[2] Z. Zhang, Y. Qin, J. Bai, X. Fu, and D. Liu, "Evaluation of favorable regions for multi-seam coal-bed methane joint exploitation based on a fuzzy model: A case study in southern Qinshui Basin, China," Energy Exploration \& Exploitation, vol. 34, no. 3, pp. 400-417, 2016.

[3] S. Shuxun, "Review on the effectiveness of carbon dioxide geological storage and coal-bed methane intensification development," Coalfield Geology and Exploration, vol. 46, no. 5, pp. 1-9, 2018.

[4] C. Zhai, B. Q. Lin, and L. Wang, "Status and problems of drainage and utilization of down hole coal bed methane in coal mines in china," Natural Gas Industry, vol. 28, no. 7, pp. 2326, 2008.

[5] Q. You, C. Wang, Q. Ding et al., "Impact of surfactant in fracturing fluid on the adsorption-desorption processes of coalbed methane," Journal of Natural Gas Science and Engineering, vol. 26, pp. 35-41, 2005.
[6] S. Zhu, L. Chuanliang, D. Zhimin, and X. Peng, "On the composite desorption model of coalbed methane," Journal of China University of Mining \& Technology, vol. 45, no. 2, pp. 319-327, 2016.

[7] L. Shouguo, J. Wenzhong, J. Baoshan, and N. Rongshan, "Application and prospect of fracturing and anti-reflection technology in low-permeability coal seams," Coal Science and Technology, vol. 45, no. 6, pp. 35-42, 2017.

[8] H. Lu, D. Zengshe, N. Baisheng, and D. Guangzhe, "High-voltage electric pulse fracturing test and its application analysis in coal-bed methane mining," Coal Mine Safety, vol. 48, no. 10, pp. 13-16, 2017.

[9] Y. Fazhi, C. Zhu, C. Guo, Z. Quanle, and Q. Shihe, "Numerical simulation and experiments on the technical parameters of synergistic permeability enhancement by slitting and fracturing," Journal of Coal, vol. 40, no. 4, pp. 823829, 2015.

[10] J. Huang, P. Fu, R. R. Settgast, J. P. Morris, and F. J. Ryerson, "Evaluating a simple fracturing criterion for a hydraulic fracture crossing stress and stiffness contrasts," Rock Mechanics and Rock Engineering, vol. 52, no. 6, pp. 16571670, 2019.

[11] H. Zhao, X. Wang, Z. Liu, Y. Yan, and H. Yang, "Investigation on the hydraulic fracture propagation of multilayerscommingled fracturing in coal measures," Journal of Petroleum Science and Engineering, vol. 167, pp. 774-784, 2018.

[12] K. Peng, H. Guo, and X. Shang, "Data field application in removing large P-phase arrival picking errors and relocating a mine microseismic event," Soil Dynamics and Earthquake Engineering, vol. 139, article 106359, 2020.

[13] X. Shang and H. Tkalčić, "Point-source inversion of small and moderate earthquakes from $\mathrm{p}$-wave polarities and P/S amplitude ratios within a hierarchical bayesian framework: Implications for the geysers earthquakes," Journal of Geophysical Research-solid Earth, vol. 125, no. 2, 2020.

[14] X. Zhong, D. Pan, L. Zhai et al., "Evaluation of the gas production enhancement effect of hydraulic fracturing on combining depressurization with thermal stimulation from challenging ocean hydrate reservoirs," Journal Of Natural Gas Science and Engineering, vol. 83, p. 103621, 2020.

[15] Z. Xihua, Z. Lijun, F. Chaojun, B. Gang, and S. Dongping, "Simulation and experimental research on hydraulic fracturing of low permeability coal seams to promote gas drainage," Chinese Safety Science Journal, vol. 27, no. 10, pp. 81-86, 2017.

[16] P. Wu, Experimental Study on Hydraulic Cracking Crack Propagation Law of Coal-Rock Composites, Taiyuan University of Technology, 2017.

[17] Z. Wang, Research on downhole hydraulic fracturing technology for low-permeability coal seams, China University of Mining and Technology, China, 2015.

[18] Q. Wang, X. Su, L. Su, H. Guo, J. Song, and Z. Zhu, “Theory and application of pseudo-reservoir hydraulic stimulation for coalbed methane indirect extraction in horizontal well: part 2-application," Natural Resources Research, vol. 29, no. 6, pp. 3895-3915, 2020.

[19] G. A. Gagnon, W. Krkosek, L. Anderson et al., "Impacts of hydraulic fracturing on water quality: a review of literature, regulatory frameworks and an analysis of information gaps," Environmental Reviews, vol. 24, no. 2, pp. 122-131, 2016. 
[20] X. Bao, The Mechanism and Experimental Study of HighVoltage Pulse Hydraulic Fracturing Coal Body, Taiyuan University of Technology, 2018.

[21] J. Shaohua, Z. Jinchang, Y. Zhiqiang, B. Decun, Y. Dong, and F. ianfeng, "Study on the time variation of water shock wavefront based on high-pressure electric pulse coal permeability enhancement," Journal of Taiyuan University of Technology, vol. 46, no. 6, pp. 680-684, 2015.

[22] Y. Zhiqiang, Z. Jinchang, B. Decun, Y. Dong, and J. Shaohua, "Study on time delay pulse discharge in water," Journal of Taiyuan University of Technology, vol. 47, no. 3, pp. 326330, 2016.

[23] L. Peipei, Basic Research on High-Voltage Electric PulseInduced Gas Drainage Technology for Borehole Water Injection, Taiyuan University of Technology, 2010.

[24] D. Yan, D. Bian, J. Zhao, and S. Niu, "Study of the electrical characteristics, shock-wave pressure characteristics, and attenuation law based on pulse discharge in water," Shock and Vibration, vol. 2016, Article ID 6412309, 11 pages, 2016.

[25] D. Yan, D. Bian, J. Zhao, Z. Yin, S. Jia, and J. Feng, "Efficiency analysis of bubble pulsation formed by high-voltage discharge in nonfree field water," Advances in Mechanical Engineering, vol. 8 , no. $8,2016$.

[26] D. Bian, J. Zhao, S. Niu, and J. Wu, "Rock fracturing under pulsed discharge homenergic water shock waves with variable characteristics and combination forms," Shock And Vibration, vol. 2018, Article ID 6236953, 11 pages, 2018.

[27] B. Decun, Y. Dong, J. Shaohua, Y. Zhiqiang, and Z. Pan, "Experiment Table of Coal Anti-reflection Based on Highvoltage Electrical Impulses," Coal Technology, vol. 34, no. 8, pp. 225-227, 2015.

[28] X. Bao, D. Yang, D. Dongming, and W. Jinwen, "Experimental and numerical simulation of coalbed methane anti-reflection by high-voltage electric pulse hydraulic fracturing method," Chinese Journal of Rock Mechanics and Engineering, vol. 36, no. 10, pp. 2415-2423, 2017.

[29] B. Xiankai, D. Dongming, C. Jiaxing, W. Jinwen, and Z. Jinchang, "Study on the effect and law of electric pulse hydraulic cracking of low permeability coal," Oil and Gas Reservoir Evaluation and Development, vol. 8, no. 5, pp. 64-69, 2018.

[30] Y. Zhao, Y. Wang, W. Wang, L. Tang, Q. Liu, and G. Cheng, "Modeling of rheological fracture behavior of rock cracks subjected to hydraulic pressure and far field stresses," Theoretical and Applied Fracture Mechanics, vol. 101, pp. 59-66, 2019.

[31] K. Peng, H. Lv, Q. Zou, Z. Wen, and Y. Zhang, "Evolutionary characteristics of mode-I fracture toughness and fracture energy in granite from different burial depths under hightemperature effect," Engineering Fracture Mechanics, vol. 239, p. 107306, 2020.

[32] Y. Wang, H. Lin, Y. Zhao, X. Li, P. Guo, and Y. Liu, "Analysis of fracturing characteristics of unconfined rock plate under edge-on impact loading," European Journal of Environmental and Civil Engineering, vol. 24, no. 14, pp. 2453-2468, 2020.

[33] S. Hu, E. Wang, and X. Kong, "Damage and deformation control equation for gas-bearing coal and its numerical calculation method," Journal of Natural Gas Science and Engineering, vol. 25, pp. 166-179, 2015.
[34] H. Liu, B. Lin, J. Mou, and W. Yang, "Mechanical evolution mechanism of coal and gas outburst," Rock Mechanics and Rock Engineering, vol. 52, no. 5, pp. 1591-1597, 2019.

[35] T. Hai, Y. Shuai, Y. Chao, W. Jianlong, D. Ansong, and Z. Zhiwei, "Micromechanical damage test in sandstone loading process," Chinese Journal of Rock Mechanics and Engineering, vol. 38, no. 3, pp. 487-498, 2019.

[36] G. Z. Voyiadjis and P. I. Kattan, "A comparative study of damage variables in continuum damage mechanics," International Journal of Damage Mechanics, vol. 18, no. 4, pp. 315-340, 2009.

[37] J.-Q. Xiao, D.-X. Ding, F.-L. Jiang, and G. Xu, "Fatigue damage variable and evolution of rock subjected to cyclic loading," International Journal of Rock Mechanics and Mining Sciences, vol. 47, no. 3, pp. 461-468, 2010.

[38] X. Liu and R. Zhou, "Investigation of the evolution of damage and permeability of coal containing gas based on acoustic emission characteristics," Asia-pacific Journal of Chemical Engineering, vol. 15, no. S1, 2020.

[39] B. Li, C. Ren, Z. Wang, J. Li, K. Yang, and J. Xu, "Experimental study on damage and the permeability evolution process of methane-containing coal under different temperature conditions," Journal of Petroleum Science and Engineering, vol. 184, p. 106509, 2020.

[40] L. Yongming and S. Mahadevan, "Stochastic fatigue damage modeling under variable amplitude loading," International Journal of Fatigu, vol. 29, no. 6, pp. 1149-1161, 2007.

[41] Y. Zhao, L. Zhang, J. Liao, W. Wang, Q. Liu, and L. Tang, "Experimental study of fracture toughness and subcritical crack growth of three rocks under different environments," International Journal of Geomechanics, vol. 20, no. 8, p. 04020128, 2020.

[42] Y. Zhao, L. Zhang, W. Wang, Q. Liu, L. Tang, and G. Cheng, "Experimental study on shear behavior and a revised shear strength model for infilled rock joints," International Journal of Geomechanics, vol. 20, no. 9, p. 04020141, 2020.

[43] Y. Zhao, C. Zhang, Y. Wang, and H. Lin, "Shear-related roughness classification and strength model of natural rock joint based on fuzzy comprehensive evaluation," International Journal of Rock Mechanics and Mining Sciences, vol. 137, article 104550, 2021.

[44] J. Wang and J. Yannan, "Integrated algorithm for distance hardening using Lemaitre's coupling elastoplastic damage model and program," Engineering Mechanics, vol. 32, no. 2, pp. 12-19, 2015.

[45] Y. Liu, D. Wang, F. Hao, M. Liu, and H. S. Mitri, "Constitutive model for methane desorption and diffusion based on pore structure differences between soft and hard coal," International Journal of Mining Science and Technology, vol. 27, no. 6, pp. 937-944, 2017.

[46] L. Changyu, L. Xiao, and W. Shuren, "Study on energy characteristics of size effect of granite under medium and low strain rate loading conditions," Rock and Soil Mechanics, vol. 37, no. 12, pp. 3472-3480, 2016.

[47] Z. Qingdong and Y. Jun, "Numerical simulation of shale hydraulic fracturing based on extended finite element method," Applied Mathematics and Mechanics, vol. 35, no. 11, pp. 1239-1248, 2014.

[48] X. Wang, Extended finite element method for numerical simulation of hydraulic fracturing in shale gas reservoirs, University of Science and Technology of China, 2017. 
[49] Z. Quansheng, Y. Gengshe, and R. Jianxi, "A new discussion on rock damage variables and constitutive equations," Chinese Journal of Rock Mechanics and Engineering, no. 1, pp. 30-34, 2003.

[50] T. Jupeng, D. Jiahui, L. Jiangwei, and Y. Ning, "Analysis of coal and gas outburst process considering effective stress," Chinese Journal of Safety Science, vol. 27, no. 9, pp. 129-133, 2017. 